\title{
On Solving Endogeneity with Invalid Instruments: An Application to Investment Equations
}

\author{
Antonio F. Galvao*, Gabriel Montes-Rojasł Jose Olmo ${ }^{\ddagger}$ and Suyong Song ${ }^{\S}$
}

February 10, 2017

\begin{abstract}
Regression models relating investment demand with firms' Tobin's $q$ and cash flow are fraught with measurement errors which, in turn, cause endogeneity bias. We propose a solution to this problem based on modeling the interaction between the endogenous Tobin's $q$ and the error term in the investment equation as a function of lagged values of Tobin's $q$. We then study the identification conditions and asymptotic properties of the resulting estimator. Our analysis of a panel of U.S. firms reveals a larger effect of Tobin's $q$ on firms' investment demand than that obtained using available estimators in the literature. Moreover, the estimates highlight the importance of cash flow. We find mixed evidence on the relationship between investment demand and firms' cash flow with respect to different measures of financial constraints. Nevertheless, this evidence is more supportive of the view that firms' cash flows have a weaker correlation to investment demand when financial conditions tighten.
\end{abstract}

Keywords: Investment equation, Endogeneity, Measurement errors, Tobin's q, Cash flow. JEL Classification: C10, C26, G31

\footnotetext{
${ }^{*}$ Department of Economics, University of Iowa, W284 Pappajohn Business Building, 21 E. Market Street, Iowa City, IA 52242. E-mail: antonio-galvao@uiowa.edu

${ }^{\dagger}$ CONICET-Universidad de San Andrés, Vito Dumas 284, Victoria, B1644, Provincia de Buenos Aires, Argentina. E-mail: gmontesrojas@udesa.edu.ar

${ }^{\ddagger}$ Corresponding author: Department of Economics, University of Southampton, Highfield Lane, Southampton, SO17 1BH. United Kingdom. E-mail: j.b.olmo@soton.ac.uk

${ }^{\S}$ Department of Economics, University of Iowa, W360 Pappajohn Business Building, 21 E. Market Street, Iowa City, IA 52242. E-mail: suyong-song@uiowa.edu
} 


\section{Introduction}

The investment theory suggests that a correct measure for firm's investment demand is marginal Tobin's q. Fazzari, Hubbard, and Petersen (1988) develop estimators for the investment equation model, where a firm's investment is regressed on a proxy for investment demand (average Tobin's q) and cash flow. Following these authors, investment-cash flow sensitivities became a standard metric in the literature to examine the impact of financing imperfections on corporate investment (Stein (2003)). ${ }^{1}$ Nevertheless, empirical models proposed to assess the sensitivity of investment demand to firm characteristics are usually fraught with the presence of measurement error. A typical example is the use of the average Tobin's $q$ for describing the investment-capital ratio or the choice of proxy variables for capturing financial frictions (Hayashi (1982)). The introduction of error when measuring these variables causes endogeneity bias in least squares estimators and leads to erroneous interpretations of the effect of firm characteristics on investment demand. Thus, Poterba (1988) introduces the idea that errors in measuring Tobin's $q$ may be responsible for the observed investment-cash flow sensitivities. If cash flow were correlated with investment opportunities, which is not well measured by a proxy for the marginal Tobin's $q$, investmentcash flow sensitivities could arise. This argument minimizes the role of financing constraints in determining the relationship between firms' cash flow and investment.

A number of studies intend to control for the measurement error in Tobin's $q$, while analyzing the relationship between investment and cash flow. A common approach has been to use the instrumental variables (IV) method together with ordinary least squares (OLS)

\footnotetext{
${ }^{1}$ These empirical sensitivities are also used for drawing inferences about efficiency in internal capital markets (Lamont (1999); Shin and Stulz (1998)), the effect of agency on corporate spending (Hadlock (1998); Bertrand and Mullainathan (2005)), the role of business groups in capital allocation (Hoshi, Kashyap, and Scharfstein (1991)), and the effect of managerial characteristics on corporate policies (Bertrand and Schoar (2003)). A related influential literature assesses the effect of financial frictions on economic growth. See Bernanke and Gertler (1989), Holmstrom and Tirole (1998), Kind and Levine (1993) and Kiyotaki and Moore (1997), among many others.
} 
and generalized method of moments (GMM) estimators to correct the endogeneity problem (see, e.g., Almeida, Campello, and Galvao (2010) and Lewellen and Lewellen (2014)). In this strand of literature, lags of the observed Tobin's $q$ are used as instruments, by assuming that they are uncorrelated with the error term in the regression equation. Specifically, Almeida, Campello, and Galvao (2010) employ GMM methods using lagged Tobin's $q$ as instruments for the measurement error problem. Their results show the importance of both Tobin's $q$ and cash flow in investment equation models.

A related method in the literature is to use different proxies to the marginal Tobin's $q$ as alternative instruments. For instance, Cummins, Hasset, and Oliner (2006) find no evidence that cash flow is a statistically significant determinant of investment in U.S. companies. Agca and Mozumdar (2016), on the other hand, find that cash flow is a statistically significant cause of investment and investment-cash flow sensitivity is higher for financially constrained firms. $^{2}$

These methods for correcting measurement errors have several shortcomings for the specific problem of estimating investment equation models. In fact, IV-based estimates might be invalid in the presence of error persistence in the structural investment regression equation, which is very likely to take place if the error term contains an autocorrelated factor. In this case, the persistent measurement error induces correlation between the IV and the error term. Hence, empirically, the standard IV corrections of the measurement error problem are inappropriate for obtaining consistent estimates of the structural parameters in the investment equation.

The main contribution of this paper is to propose an alternative solution to the measure-

\footnotetext{
${ }^{2}$ An alternative solution relies on the high-order moments. This body of the literature addresses the issue by developing measurement error-consistent GMM estimators based on the third-and higher-order moments of the joint distribution of the observed variables (see, e.g., Erickson and Whited (2000)). The high-order methods, however, rely on very strong conditions on unobservables and provide unstable and biased coefficient estimates in the presence of fixed-effects under heteroscedasticity, or in the absence of a high degree of skewness in the data.
} 
ment error problem in investment models that explicitly exploits the presence of persistence in the error term. By doing so we develop an econometric methodology that is suitable for assessing the effect of firm characteristics measured with error on investment demand. Our solution is based on modeling the joint interaction of the endogenous variable, e.g. average Tobin's $q$, and the error term as a function of polynomials of the lags of Tobin's $q$. The framework allows for situations in which there are no valid standard instruments available, but there exist additional variables that are related to the joint interaction of the endogenous variable and the unobserved causes of the dependent variable. These additional variables are defined as simultaneous variables. The intuition of the main identification condition is that, by using the proposed restriction, the researcher is able to approximate the endogeneity bias using the simultaneous variables. We state sufficient conditions on the primitives for the identification of regression coefficients. Motivated by this identification result, we suggest an estimator of the structural parameters based on moment conditions that arise from the use of the structural investment equation and an additional equation proposed under our correction method. We also derive consistency and asymptotic normality of the estimator, and develop inference procedures.

We apply this methodology to a panel of U.S. firms over the period of 1974 to 2010, and observe large differences across estimates of the effects of Tobin's average $q$ and firms' cash flow. Our empirical findings invalidate the use of OLS and IV estimators due to the presence of serial persistence in the error term of the investment regression equation. In contrast, our novel estimation procedure reports estimates of the Tobin's average $q$ coefficient significantly larger than the OLS, IV and GMM counterparts. The parameter associated to firms' cash flow is also statistically significant suggesting that firm's cash flow adds relevant information above and beyond that provided by Tobin's $q$ for describing firms' investment demand.

To obtain deeper insights into the role of cash flow and the relation with financial con- 
straints, we also classify firms into constrained and unconstrained using several of the criteria proposed in Almeida, Campello, and Weisbach (2004), Moyen (2004) and Hadlock and Pierce (2010). The results of our empirical analysis provide mixed evidence of the relationship between cash flow and financial constraints that, nevertheless, is consistent with the existing literature on the role of cash flow sensitivities in investment demand. More specifically, we find a higher sensitivity of investment to cash flow for financially constrained firms, as characterized by smaller and younger firms. These results are consistent with Fazzari, Hubbard, and Petersen (1988), Almeida, Campello, and Weisbach (2004) and Hadlock and Pierce (2010). Interestingly, we find the opposite result, consistent with Kaplan and Zingales (1997), when financial constraints are characterized by variables related to firms' payout ra-

tios and dividends. An additional robustness exercise consists in analysing the effect of a credit supply shock on the relationship between investment demand and firms' cash flow. This analysis shows that firms' cash flow has a weaker correlation to investment demand when financial conditions tighten.

The paper is organized as follows. Section 2 overviews the measurement error problem in investment models. Section 3 presents our solution to correct for endogeneity, derives a feasible estimator, and develops inference. Section 4 presents empirical evidence on the drivers of firm's investment using a panel of U.S. firms. Finally, Section 5 concludes the paper. The Appendix contains technical proofs and a discussion on why the IV estimator is inconsistent in the presence of measurement errors' serial persistence.

\section{Measurement errors and endogeneity}

In this section, we discuss why measurement errors on the marginal Tobin's $q$ are common, and why conventional instrumental variables (IV) methods are not able to control for them under persistent measurement errors. 


\subsection{Measurement errors on marginal Tobin's $q$}

The theory suggests that the correct measure for a firm's investment demand is captured by marginal Tobin's $q$. This measure stems from the relationship that equates firm's marginal benefit with marginal cost in equilibrium. ${ }^{3}$ Nevertheless, the presence of financial constraints may distort this relationship by introducing other factors that influence the firm's optimal investment level. More specifically, financial constraints create a wedge between internal and external funding that invalidates theoretical arguments in the spirit of Modigliani and Miller (1958) capital structure irrelevance proposition. In this scenario, a firm's cash flow reflects the presence of financial constraints and may contain information relevant for explaining the differences in investment demand across firms.

Fazzari, Hubbard, and Petersen (1988) propose a regression specification of the investment equation that allows the inclusion of additional explanatory variables to explain variation in the investment-capital ratio as follows:

$$
y_{i t}=\alpha+\beta q_{i t}^{*}+\gamma C F_{i t}+\eta_{i t}, \quad i=1, \ldots, n ; t=1, \ldots, T,
$$

with $y_{i t} \equiv I_{i t} / K_{i t}$ the investment-capital ratio, $C F_{i t} \equiv c f_{i t} / K_{i t}$ the cash flow-capital ratio, $q_{i t}^{*}$ represents the quantity "marginal $q$ ", and $\eta_{i t}$ the idiosyncratic structural error term, which is assumed to be a mean-zero white noise.

The $q_{i t}^{*}$ quantity is unobservable and researchers use instead its measurable counterpart, average Tobin's q. Hayashi (1982) shows analytically the differences between these quantities for different production and cost functions. More specifically, he shows that

$$
q_{i t}^{a}=\lambda_{i t}+q_{i t}^{*},
$$

where $q_{i t}^{a}$ denotes Tobin's average $q$ and $\lambda_{i t}$ is a quantity that captures the present discounted

\footnotetext{
${ }^{3}$ We refer the readers to Abel and Eberly (1994) and Erickson and Whited (2000) for a discussion on a microfounded model based on the neoclassical theory of investment that helps in the motivation of the relationship between Tobin's q and firms' investment demand.
} 
value of current and future tax deductions attributable to past investments for a production function exhibiting constant returns to scale and a cost function homogeneous of order one. The quantity $\lambda_{i t}$ captures other features of the production function such as the elasticity of demand for the firm's output for different market structures, for example, when firms are price makers.

Further, following Cummins, Hasset, and Oliner (2006), it is also possible to accommodate the possibility of measurement error in the average Tobin's $q$. Consider the following specification for the observed Tobin's $q$

$$
q_{i t}=q_{i t}^{a}+\nu_{i t}
$$

where $q_{i t}$ is the observable average Tobin's $q$, which is measured as the average Tobin's $q$, $q_{i t}^{a}$, plus the error $\nu_{i t}$. The above expressions imply

$$
q_{i t}^{*}=q_{i t}-e_{i t}
$$

with $e_{i t}=\lambda_{i t}+\nu_{i t}$ denoting a modified measurement error term. Then, plugging equation (3) into the investment model (1), we obtain

$$
\begin{aligned}
y_{i t} & =\alpha+\beta\left(q_{i t}-e_{i t}\right)+\gamma C F_{i t}+\eta_{i t} \\
& =\alpha+\beta q_{i t}+\gamma C F_{i t}+\epsilon_{i t},
\end{aligned}
$$

where $\epsilon_{i t} \equiv \eta_{i t}-\beta e_{i t}$ is correlated with $q_{i t}$ by the presence of the measurement error. This correlation leads to endogeneity of the regressors and inconsistent parameter estimates. Furthermore, if $q_{i t}$ is correlated with the observable exogenous variables $C F_{i t}$ then the above regression equation would also entail the correlation between $C F_{i t}$ and $\epsilon_{i t}$ and the inconsistency of $\gamma$. We will assume hereafter that cash flow is measured without error and, hence, uncorrelated with the error term $\epsilon_{i t}$. 


\subsection{Failure of IV methods}

It has been common in the literature to employ IV estimators to resolve the statistical problems induced by the presence of endogeneity in investment equation models. Almeida, Campello, and Galvao (2010) show that, under some conditions, IV methods deliver estimated coefficients that are robust and economically meaningful. These estimators employ lags of $q_{i t}$ as instruments for the endogenous variable $q_{i t}$.

Almeida, Campello, and Galvao (2010) discuss the assumptions on the dynamics of the measurement error to make IV methods valid. These authors find that if the measurement error $e_{i t}$ in equation (3) is independent and identically distributed (i.i.d.) across firms and time, and $q_{i t}$ is serially correlated, then, lags of the variable with errors (for example, $q_{i t-2}$, $q_{i t-3}$, or $\left.\left(q_{i t-2}-q_{i t-3}\right)\right)$ are valid instruments for $q_{i t}$ since they are correlated with $q_{i t}$ (instrument relevance condition) but uncorrelated with the error term $\epsilon_{i t}$ (instrument exogeneity condition).

However, when both the marginal Tobin's $q$ and its measurement errors exhibit serial persistence, the IV approach which employs the lags of the mismeasured Tobin's $q$ as instruments fails to solve the endogeneity problem. In this case, as further discussed in Appendix $\mathrm{B}$, the instrument exogeneity condition is no longer valid because the IV (the lags of mismeasured Tobin's q) are correlated with the regression error term.

\section{Econometric methodology}

This section suggests an alternative method to obtain consistent parameter estimates in the investment equation model. The proposed methodology introduces an auxiliary equation that models the interaction term $q_{i t} \epsilon_{i t}$ as a function of observable covariates. These covariates are determined by polynomials of lagged values of average Tobin's $q$, and their use is 
motivated by the persistence of both the measurement error variable and marginal Tobin's q. The second part of the section suggests an estimator based on the empirical counterpart of the identification result and develops inference procedures.

\subsection{Econometric model and identification}

\subsubsection{A preview of the solution}

For simplicity, we outline first the identification strategy of the structural parameters for the simple case given by an investment equation that only depends on the marginal Tobin's $q$. Consider the following simplified model

$$
y_{i t}=\beta q_{i t}+\epsilon_{i t},
$$

where $\epsilon_{i t} \equiv \eta_{i t}-\beta e_{i t}$ and $e_{i t}=\lambda_{i t}+\nu_{i t}$. Assume there exists a set of observable variables $Z_{i t}$ such that

$$
\mathrm{E}\left[q_{i t} \epsilon_{i t} \mid q_{i t}, \boldsymbol{Z}_{i t}\right]=\boldsymbol{Z}_{i t} \boldsymbol{\phi}
$$

with $\phi$ being a vector of parameters different from zero. This condition introduces an auxiliary equation given by

$$
q_{i t} \epsilon_{i t}=\boldsymbol{Z}_{i t} \boldsymbol{\phi}+u_{i t}
$$

where $u_{i t}$ is an error term orthogonal to $\boldsymbol{Z}_{i t}$ and $q_{i t}^{2}$, by construction.

Given the equation (7), the intuition of the solution is as follows. Note that $\epsilon_{i t}$ is not observable, however, from (5) and (7), $q_{i t} \epsilon_{i t}$ can be rewritten through the equation

$$
q_{i t} y_{i t}=\beta q_{i t}^{2}+q_{i t} \epsilon_{i t}=\beta q_{i t}^{2}+\boldsymbol{Z}_{i t} \boldsymbol{\phi}+u_{i t}
$$

The structural parameters of the investment equation can be identified through the intro- 
duction of the auxiliary equation (6). In order to see this note that from (5) and (7)

$$
\begin{aligned}
u_{i t} & =q_{i t} \epsilon_{i t}-\boldsymbol{Z}_{i t} \boldsymbol{\phi} \\
& =q_{i t}\left(y_{i t}-\beta q_{i t}\right)-\boldsymbol{Z}_{i t} \boldsymbol{\phi} \\
& =q_{i t} y_{i t}-\tilde{\boldsymbol{q}}_{i t}\left[\beta, \boldsymbol{\phi}^{\top}\right]^{\top},
\end{aligned}
$$

where $\tilde{\boldsymbol{q}}_{i t} \equiv\left[q_{i t}^{2}, \boldsymbol{Z}_{i t}\right]$. We then consider the moment equation

$$
\mathrm{E}\left[\tilde{\boldsymbol{q}}_{i t}^{\top} u_{i t}\right]=0
$$

so that we obtain $\mathrm{E}\left[\tilde{\boldsymbol{q}}_{i t}^{\top}\left(q_{i t} y_{i t}-\tilde{\boldsymbol{q}}_{i t}\left[\beta, \boldsymbol{\phi}^{\top}\right]^{\top}\right)\right]=0$. Finally, by distributing the expectation, we have that

$$
\mathrm{E}\left[\tilde{\boldsymbol{q}}_{i t}^{\top} q_{i t} y_{i t}\right]=\mathrm{E}\left[\tilde{\boldsymbol{q}}_{i t}^{\top} \tilde{\boldsymbol{q}}_{i t}\right]\left[\beta, \boldsymbol{\phi}^{\top}\right]^{\top}
$$

Given non-singularity of $\mathrm{E}\left[\tilde{\boldsymbol{q}}_{i t}^{\top} \tilde{\boldsymbol{q}}_{i t}\right]$, this moment equation uniquely identifies $\beta$ and $\boldsymbol{\phi}$.

\subsubsection{General methodology}

In what follows, we extend and formalize the above results and also accommodate an exogenous regressor, i.e., $C F_{i t}$. Identification of the parameters of interest is achieved by explicitly modeling the interaction of the endogenous variable and the unobserved causes of the dependent variable as a function of additional observable variables. In particular, we consider the case where the variable $q_{i t} \epsilon_{i t}$ can be modeled using additional variables. For notational simplicity, we suppress the subscripts $(i, t)$ whenever there is no confusion. The following equation formalizes modeling endogeneity

$$
\mathrm{E}(q \epsilon \mid \boldsymbol{z}, \boldsymbol{x})=g(\boldsymbol{z}),
$$

where $g(\cdot)$ is an unknown smooth function $\boldsymbol{z}$, a $k$-vector of additional observable variables, and $\boldsymbol{x}$ is the set of regressors, in this case $\boldsymbol{x}=[1, C F, q]$. This is a general formulation to 
model the endogeneity in the linear parametric model. For simplicity, we assume that $g(\cdot)$ is a known function of $\boldsymbol{z}$ with unknown parameters $\phi$ such as $g(\boldsymbol{z} ; \phi)$. But the analysis can be extended to the case of unknown functional form of $g(\cdot)$, as one might approximate the unknown function $g(\cdot)$ with one of the sieve bases (e.g., power series, Fourier series, splines, etc.). ${ }^{4}$

A simple example of (8) that is convenient for exposition and estimation purposes is to assume the following polynomial approximation for $g(\boldsymbol{z})$,

$$
\mathrm{E}(q \epsilon \mid \boldsymbol{z}, \boldsymbol{x})=\boldsymbol{Z} \boldsymbol{\phi}
$$

where $\boldsymbol{Z}=\left[1, \boldsymbol{z}, \boldsymbol{z}^{2}, \ldots, \boldsymbol{z}^{m}\right]$ and $\boldsymbol{\phi}=\left[\phi_{0}, \boldsymbol{\phi}_{1}^{\top}, \ldots, \boldsymbol{\phi}_{m}^{\top}\right]^{\top}$ which is a nonzero vector with $\boldsymbol{\phi} \neq \mathbf{0}$. Equation (9) is explicitly modeling the endogeneity of $q$ and requires observable variables, $\boldsymbol{z}$, the simultaneous variables. We are interested in identifying and estimating the parameters $(\beta, \gamma)$ in equation (1). In practice, $\boldsymbol{\phi}$ is unknown, and it is important to note that this parameter cannot be directly estimated from equation (9) because $\epsilon$ is unobservable. Hence, we consider the joint identification and estimation of both $(\beta, \gamma)$ and $\phi$.

Consider now the structural model in equation (1) and define $\boldsymbol{\theta} \equiv\left[\alpha, \gamma, \beta, \boldsymbol{\phi}^{\top}\right]^{\top}, \boldsymbol{\theta}_{1} \equiv$ $[\alpha, \gamma]^{\top}$ and $\boldsymbol{\theta}_{\mathbf{2}} \equiv\left[\beta, \boldsymbol{\phi}^{\top}\right]^{\top}, \boldsymbol{x} \equiv[1, C F, q]$ and $\boldsymbol{x}_{1} \equiv(1, C F)$. To ease notation, define $\tilde{y}$ and $\tilde{q}$ after netting out the exogenous regressor $\boldsymbol{x}_{1}$ and multiplying the resulting objects by $q$. Let $\tilde{y}=q\left(y-\boldsymbol{x}_{1} \mathrm{E}\left(\boldsymbol{x}_{1}^{\top} \boldsymbol{x}_{1}\right)^{-1} \mathrm{E}\left(\boldsymbol{x}_{1}^{\top} y\right)\right)$ and $\tilde{\boldsymbol{x}}=[\tilde{q}, \boldsymbol{Z}]$, with $\tilde{q}=q\left(q-\boldsymbol{x}_{1} \mathrm{E}\left(\boldsymbol{x}_{1}^{\top} \boldsymbol{x}_{1}\right)^{-1} \mathrm{E}\left(\boldsymbol{x}_{1}^{\top} q\right)\right)$ and $\boldsymbol{Z}=\left[1, \boldsymbol{z}, \boldsymbol{z}^{2}, \ldots, \boldsymbol{z}^{m}\right]$. Further, consider the following assumptions:

\section{Assumption 1}

(i) The variable $\boldsymbol{x}_{1}$ is exogenous such that $\mathrm{E}\left(\boldsymbol{x}_{1}^{\top} \epsilon\right)=\mathbf{0}$;

(ii) The matrices $\mathrm{E}\left(\boldsymbol{x}_{1}^{\top} \boldsymbol{x}_{1}\right)$ and $\mathrm{E}\left(\tilde{\boldsymbol{x}}^{\top} \tilde{\boldsymbol{x}}\right)$ are non-singular;

(iii) We have $q \epsilon=\boldsymbol{Z} \boldsymbol{\phi}+u$, where $\boldsymbol{\phi} \neq \mathbf{0}$ and $\mathrm{E}\left(\tilde{\boldsymbol{x}}^{\top} u\right)=\mathbf{0}$.

\footnotetext{
${ }^{4}$ See, e.g., Chen (2007) for more details on the method of sieve.
} 
Assumption $1(i)$ states that $C F$ (i.e., cash flow) is an exogenous regressor. In practice, we propose to use polynomials of lagged values of average Tobin's $q$ as $\boldsymbol{Z}$. Thus, Assumption $1(i i)$ is satisfied if $\tilde{q}_{i t}$ is not perfectly linearly related to $q_{i t-1}, q_{i t-1}^{2}$, and its higher order terms. Finally, Assumption 1 (iii) means that $\mathrm{E}\left(\left[q_{i t-1}, q_{i t-1}^{2}, \ldots, q_{i t-1}^{m}\right] u_{i t}\right)=0$ and $\mathrm{E}\left(\tilde{q}_{i t} u_{i t}\right)=0$ hold, where $\tilde{q}_{i t}$ is the product of $q_{i t}$ and $q_{i t}$ with $C F_{i t}$ netted out. Assumption $1(i)$ is a standard condition in the corporate finance literature, and Assumption 1 (ii) is satisfied in practice. The two conditions in Assumption 1 ( iii) crucially depend on the validity of $\boldsymbol{Z}$. In particular, the conditions depend on $u_{i t}$, the residual projection of $q \epsilon$ on $\boldsymbol{Z}$, being uncorrelated with $\tilde{\boldsymbol{x}}_{i t}$, where $\tilde{\boldsymbol{x}}=[\tilde{q}, \boldsymbol{Z}]$ with $\tilde{q}=q\left(q-\boldsymbol{x}_{1} \mathrm{E}\left(\boldsymbol{x}_{1}^{\top} \boldsymbol{x}_{1}\right)^{-1} \mathrm{E}\left(\boldsymbol{x}_{1}^{\top} q\right)\right)$. The identification condition 1 (iii) requires that $\boldsymbol{Z}$ captures as much information as possible on $q \epsilon$ so that the remainder is not further correlated with the square of $q$ (after $C F$ has been netted out). We expect that lags of $q_{i t}$ contain useful information on $q_{i t}$ in the presence of autoregressive time structure or any other persistent process. The following theorem formalizes the identification results.

Theorem 1 Suppose Assumption 1 holds. Then, $\boldsymbol{\theta}$ is uniquely identified as

$$
\begin{aligned}
& \boldsymbol{\theta}_{1}=\mathrm{E}\left(\boldsymbol{x}_{1}^{\top} \boldsymbol{x}_{1}\right)^{-1} \mathrm{E}\left(\boldsymbol{x}_{1}^{\top} y\right)-\mathrm{E}\left(\boldsymbol{x}_{1}^{\top} \boldsymbol{x}_{1}\right)^{-1} \mathrm{E}\left(\boldsymbol{x}_{1}^{\top} q\right) \beta, \\
& \boldsymbol{\theta}_{2}=\mathrm{E}\left(\tilde{\boldsymbol{x}}^{\top} \tilde{\boldsymbol{x}}\right)^{-1} \mathrm{E}\left(\tilde{\boldsymbol{x}}^{\top} \tilde{y}\right) .
\end{aligned}
$$

It remains to address the empirical question of choosing an appropriate set of observable variables for $\boldsymbol{Z}$. The strategy pursued in this paper allows, contrary to IV methods, for both $q^{*}$ and $e$ to be autocorrelated such that lags of $q$ can be used to achieve identification and produce consistent estimates of the parameters of interest. A correlation condition seems very natural in this context if we consider that Tobin's $q$ and, potentially $\lambda_{t}$ in $(2)$, are both persistent over time. Thus, the main objective is to verify Assumption 1 (iii) under a correlation condition. We formalize the result in the following proposition for the investment equation where both $q^{*}$ and $e$ are allowed to be autocorrelated. We consider the investment 
equation (5) that only depends on Tobin's $q$, and the exogenous regressor, cash flow $(C F)$, can be straightforwardly included by changing the notation à la Theorem 1 .

Proposition 1 Suppose the sequence of measurement errors follows $e_{i t}=h\left(e_{i t-1}, q_{i t-1}^{*}\right)$ for a measurable function $h, q_{i t}^{*}$ is autocorrelated, and $g\left(\boldsymbol{z}_{i t}\right)$ can be approximated by a polynomial of order m. Then, Assumption 1 (iii) is satisfied, that is,

$$
q_{i t} \epsilon_{i t}=Z_{i t} \phi+u_{i t}
$$

where $\mathrm{E}\left[\tilde{\boldsymbol{x}}_{i t}^{\top} u_{i t}\right]=0$ with $\tilde{\boldsymbol{x}}_{i t} \equiv\left[q_{i t}^{2}, \boldsymbol{Z}_{i t}\right], \boldsymbol{Z}_{i t} \equiv\left[1, q_{i t-1}, q_{i t-1}^{2}, \ldots, q_{i t-1}^{m}\right]$ and $u_{i t} \equiv q_{i t} \eta_{i t}-$ $\beta q_{i t} e_{i t}-\mathrm{E}\left[\beta q_{i t} e_{i t} \mid \boldsymbol{z}_{i t}\right]$.

First, the assumption on $e_{i t}$ in Proposition 1 imposes an autocorrelation model on the measurement errors. It also allows for the dependence between the lags of true Tobin's $q$ and the measurement error. The interpretation of this assumption is intuitive. Notice that in $e_{i t}=h\left(e_{i t-1}, q_{i t-1}^{*}\right)$ the variable $q_{i t-1}^{*}$ is unobserved and could be interpreted as an innovation shock, which means that the shock to the measurement error process of Tobin's $q$ is driven by the past values of the true unobserved Tobin's $q$. The assumption on $e_{i t}$ also encompasses nonclassical measurement errors in that the true Tobin's $q$ is correlated with measurement error (or true Tobin's $q$ affects levels of measurement error). This is very useful in practice since the size of the measurement error could depend on the level of true Tobin's $q$ (or firm's expected stream of future marginal benefits from using capital). For instance, the larger the true $q^{*}$, the lower the measurement error since larger firms usually have more refined accounting systems. Note that the condition on $e_{i t}$ invalidates the instrument exogeneity condition in the IV model, but it is a key element in the proposed estimator. Second, the assumption on $q_{i t}^{*}$ being autocorrelated is mild and only used to guarantee that the lags of observed Tobin's $q$ are valid simultaneous variables. Finally, the condition that $g\left(\boldsymbol{z}_{i t}\right)$ can be approximated by a polynomial is commonly used in empirical applications. 
We notice that the result in Proposition 1 implies that under the stated conditions Assumption $1($ iii $)$ is satisfied, and hence a polynomial of the lags of average $q$ serves as covariates to model the endogeneity implied by the measurement errors in the investment equation model. The intuition behind this result is that the first-order lag of mismeasured $q_{i t}$ contains sufficient information on the interaction of mismeasured $q_{i t}$ and the regression error term $\epsilon_{i t}$.

\subsection{Estimation and inference}

In this section we construct an estimator which is simple to implement in practice, and derive its asymptotic properties. We define this estimator as the S-estimator as we are specifically modeling the simultaneous covariance between the endogenous variable and the error term.

An estimator of $\boldsymbol{\theta}$ motivated by results in Theorem 1 is

$$
\begin{aligned}
\widehat{\boldsymbol{\theta}}_{1} & =\left(\frac{1}{n} \sum_{i=1}^{n} \sum_{t=1}^{T} \boldsymbol{x}_{1 i t}^{\top} \boldsymbol{x}_{1 i t}\right)^{-1}\left(\frac{1}{n} \sum_{i=1}^{n} \sum_{t=1}^{T} \boldsymbol{x}_{1 i t}^{\top} y_{i t}\right)-\left(\frac{1}{n} \sum_{i=1}^{n} \sum_{t=1}^{T} \boldsymbol{x}_{1 i t}^{\top} \boldsymbol{x}_{1 i t}\right)^{-1}\left(\frac{1}{n} \sum_{i=1}^{n} \sum_{t=1}^{T} \boldsymbol{x}_{1 i t}^{\top} q_{i t}\right) \widehat{\beta}, \\
\widehat{\boldsymbol{\theta}}_{2} & =\left(\frac{1}{n} \sum_{i=1}^{n} \sum_{t=1}^{T} \widehat{\boldsymbol{x}}_{i t}^{\top} \widehat{\boldsymbol{x}}_{i t}\right)^{-1}\left(\frac{1}{n} \sum_{i=1}^{n} \sum_{t=1}^{T} \widehat{\boldsymbol{x}}_{i t}^{\top} \widehat{y}_{i t}\right),
\end{aligned}
$$

where $\widehat{x}$ and $\widehat{y}$ are sample analogs of $\tilde{x}$ and $\tilde{y}$, which are obtained by replacing the expec-

tations with sample means, and where $\widehat{\beta}$ is the first element of $\widehat{\boldsymbol{\theta}_{2}}$. Implementation of the proposed estimator is simple and can be carried through a sequence of OLS estimations. First, compute $\widehat{x}$ and $\widehat{y}$ and estimate $\widehat{\boldsymbol{\theta}}_{2}$ using OLS. These generated variables affect the asymptotic variance-covariance matrix (see e.g. Pagan, 1984). Finally, given $\widehat{\beta}, \widehat{\boldsymbol{\theta}}_{1}$ can be estimated by OLS.

Define $Q \equiv \mathrm{E}\left(\tilde{\boldsymbol{x}}_{i t}^{\top} \tilde{\boldsymbol{x}}_{i t}\right), \boldsymbol{C}_{1} \equiv \mathrm{E}\left(\boldsymbol{x}_{1 i t}^{\top} \boldsymbol{x}_{1 i t}\right)$, and $C_{2} \equiv \mathrm{E}\left(\boldsymbol{x}_{1 i t}^{\top} q_{i t}\right)$. To establish the asymptotic properties of the estimator, consider the following assumptions. For simplicity, we consider a balanced panel and the case of large $n$ and fixed $T$. 


\section{Assumption 2}

(i) The data $\left\{\left(y_{i t}, \boldsymbol{x}_{i t}, \boldsymbol{Z}_{i t}\right) ; i=1,2, \ldots, n, t=1,2, \ldots, T\right\}$ is i.i.d. across $i$;

(ii) We have $\mathrm{E}\left(\left\|y_{i t}\right\|^{4}\right)<\infty, \mathrm{E}\left(\left\|\boldsymbol{x}_{i t}\right\|^{4}\right)<\infty$, and $\mathrm{E}\left(\left\|\boldsymbol{Z}_{i t}\right\|^{4}\right)<\infty$;

(iii) The matrices $Q$ and $\boldsymbol{C}_{1}$ are nonsingular.

The asymptotic properties of the S-estimator are summarized in the following result.

Theorem 2 Let Assumptions 1 and 2 hold with $\mathrm{E}(u \mid \tilde{\boldsymbol{x}})=0$ in place of $\mathrm{E}\left(\tilde{\boldsymbol{x}}^{\top} u\right)=0$. Then, as $n \rightarrow \infty$,

$$
\widehat{\boldsymbol{\theta}_{1}} \stackrel{p}{\rightarrow} \boldsymbol{\theta}_{1}, \quad \widehat{\boldsymbol{\theta}_{2}} \stackrel{p}{\rightarrow} \boldsymbol{\theta}_{2}
$$

and

$$
\sqrt{n}\left(\widehat{\boldsymbol{\theta}}_{1}-\boldsymbol{\theta}_{1}\right) \stackrel{d}{\rightarrow} N\left(0, \boldsymbol{C}_{1}^{-1} C_{2} V_{\widehat{\beta}} C_{2}^{\top} \boldsymbol{C}_{1}^{-1}\right), \quad \sqrt{n}\left(\widehat{\boldsymbol{\theta}_{2}}-\boldsymbol{\theta}_{2}\right) \stackrel{d}{\rightarrow} N\left(0, Q^{-1} M Q^{-1}\right)
$$

with $V_{\widehat{\beta}}=\operatorname{Var}(\widehat{\beta})$ and $M=\operatorname{Var}\left(\tilde{\boldsymbol{x}}^{\top} u-G r\left(\delta_{q}\right)+H s\left(\delta_{y}\right)\right)$, where $G, r\left(\delta_{q}\right), H$, and $s\left(\delta_{y}\right)$ are defined in the proof.

Given the result in Theorem 2, general hypotheses on the vector $\boldsymbol{\theta}$ can be easily accommodated by Wald-type tests. The Wald process and associated limiting theory provide a natural foundation for testing the linear null hypothesis $H_{0}: R \boldsymbol{\theta}=r$, when $r$ is known. In practice, to carry out inference and apply a Wald-type test one needs a consistent estimator of the asymptotic variance matrix. As described in the above result, to estimate the asymp-

totic variance-covariance matrix, we need to estimate both $\operatorname{Var}\left(\widehat{\boldsymbol{\theta}}_{2}\right)=Q^{-1} M Q^{-1} / n$ and $\operatorname{Var}\left(\widehat{\boldsymbol{\theta}}_{1}\right)=\boldsymbol{C}_{1}^{-1} C_{2} V_{\beta} C_{2} \boldsymbol{C}_{1}^{-1} / n$. The latter is easily recovered from its sample counterparts, that is,

$$
\boldsymbol{C}_{1}=\frac{1}{n} \sum_{i=1}^{n} \sum_{t=1}^{T} \boldsymbol{x}_{1 i t}^{\top} \boldsymbol{x}_{1 i t}, \quad C_{2}=\frac{1}{n} \sum_{i=1}^{n} \sum_{t=1}^{T} \boldsymbol{x}_{1 i t}^{\top} q_{i t} .
$$


In addition, $V_{\widehat{\beta}}$ is the first element of the variance-covariance matrix $\operatorname{Var}\left(\widehat{\boldsymbol{\theta}}_{2}\right)$. Finally, for the estimation of the variance-covariance matrix of $\widehat{\boldsymbol{\theta}}_{2}$ one can consider its sample counterpart such as $\widehat{\operatorname{Var}}\left(\widehat{\boldsymbol{\theta}}_{2}\right)=\widehat{Q}^{-1} \widehat{M} \widehat{Q}^{-1} / n$ with

$$
\begin{gathered}
\widehat{Q}=\frac{1}{n} \sum_{i=1}^{n} \sum_{t=1}^{T} \widehat{\boldsymbol{x}}_{i t}^{\top} \widehat{\boldsymbol{x}}_{i t} \\
\widehat{M}=\frac{1}{n} \sum_{i=1}^{n} \sum_{t=1}^{T}\left(\widehat{\boldsymbol{x}}_{i t}^{\top} \widehat{u}_{i t}-\widehat{G} \widehat{r}_{i t}\left(\delta_{q}\right)+\widehat{H} \widehat{s}_{i t}\left(\delta_{y}\right)\right)\left(\widehat{\boldsymbol{x}}_{i t}^{\top} \widehat{u}_{i t}-\widehat{G} \widehat{r}_{i t}\left(\delta_{q}\right)+\widehat{H} \widehat{s}_{i t}\left(\delta_{y}\right)\right)^{\top}
\end{gathered}
$$

where

$$
\begin{gathered}
\widehat{u}_{i t}=\widehat{y}_{i t}-\widehat{\boldsymbol{x}}_{i t} \widehat{\boldsymbol{\theta}}_{2} \\
\widehat{G}=\frac{1}{n} \sum_{i=1}^{n} \sum_{t=1}^{T}\left(\tilde{\boldsymbol{x}}_{i t}^{\top} \nabla_{\delta_{q}} \tilde{\boldsymbol{x}}_{i t} \widehat{\boldsymbol{\theta}}_{2}\right)=\frac{1}{n} \sum_{i=1}^{n} \sum_{t=1}^{T}\left(\widehat{\boldsymbol{x}}_{i t}^{\top}\left[-q_{i t} \boldsymbol{x}_{1 i t}, 0,0\right] \widehat{\boldsymbol{\theta}}_{2}\right), \\
\widehat{H}=\frac{1}{n} \sum_{i=1}^{n} \sum_{t=1}^{T}\left(\tilde{\boldsymbol{x}}_{i t}^{\top} \nabla_{\delta_{y}} \tilde{y}_{i t}\right)=\frac{1}{n} \sum_{i=1}^{n} \sum_{t=1}^{T}\left(\widehat{\boldsymbol{x}}_{i t}^{\top}\left(-q_{i t} \boldsymbol{x}_{1 i t}\right)\right), \\
\widehat{r}_{i t}\left(\widehat{\delta}_{y}\right)=\left(\frac{1}{n} \sum_{i=1}^{n} \sum_{t=1}^{T} \boldsymbol{x}_{1 i t}^{\top} \boldsymbol{x}_{1 i t}\right)^{-1}\left(\boldsymbol{x}_{1 i t}^{\top}\left(q_{i t}-\boldsymbol{x}_{1 i t} \widehat{\delta}_{q}\right)\right) \\
\widehat{s}_{i t}\left(\widehat{\delta}_{y}\right)=\left(\frac{1}{n} \sum_{i=1}^{n} \sum_{t=1}^{T} \boldsymbol{x}_{1 i t}^{\top} \boldsymbol{x}_{1 i t}\right)^{-1}\left(\boldsymbol{x}_{1 i t}^{\top}\left(y_{i t}-\boldsymbol{x}_{1 i t} \widehat{\delta}_{y}\right)\right) \\
\widehat{\delta}_{q}=\left(\frac{1}{n} \sum_{i=1}^{n} \sum_{t=1}^{T} \boldsymbol{x}_{1 i t}^{\top} \boldsymbol{x}_{1 i t}\right)^{-1}\left(\frac{1}{n} \sum_{i=1}^{n} \sum_{t=1}^{T} \boldsymbol{x}_{1 i t}^{\top} q_{i t}\right)
\end{gathered}
$$

and

$$
\widehat{\delta}_{y}=\left(\frac{1}{n} \sum_{i=1}^{n} \sum_{t=1}^{T} \boldsymbol{x}_{1 i t}^{\top} \boldsymbol{x}_{1 i t}\right)^{-1}\left(\frac{1}{n} \sum_{i=1}^{n} \sum_{t=1}^{T} \boldsymbol{x}_{1 i t}^{\top} y_{i t}\right)
$$

\section{Empirical analysis for a panel of U.S. firms}

The purpose of this empirical analysis is twofold. First, we compare and statistically assess

the parameter estimates determining the relationship between corporate investment demand, Tobin's $q$ and firms' cash flow obtained under different estimation procedures. We highlight 
the differences between existing procedures such as OLS, IV and GMM and our novel Sestimator. Second, we carry out an exhaustive exercise to determine the effect of firms' cash flow on investment demand, and assess whether this relationship depends on the extent of financial constraints faced by firms. To do this, we estimate the investment regression equation for different subsamples of financially constrained and unconstrained firms classified according to different criteria as set out in Almeida, Campello, and Weisbach (2004), Moyen (2004) and Hadlock and Pierce (2010).

\subsection{Data}

The data is taken from COMPUSTAT and covers the period 1974 to 2010. The data collection process follows an extension of that of Almeida and Campello (2007). The sample consists of manufacturing firms with fixed capital of more than $\$ 5$ million (with 1974 as the base year for the consumer price index). Firms in the sample have growth of less than $100 \%$ in both assets and sales. We keep observations with at least 3 lags. Summary statistics for investment and cash flow are presented in Table 1. These statistics are similar to those reported by Almeida and Campello (2007), among other papers. Note that the sample corresponds to an unbalanced panel of 3085 firms, with an average number of observations per firm of 10.60. To save space, we omit the discussion of these descriptive statistics.

\section{[TABLE 1 ABOUT HERE]}

\subsection{Empirical results}

\subsubsection{Comparison of estimation methods}

We use first simple estimators that do not correct for measurement errors (ME) as ordinary least squares (OLS) and least squares fixed-effects (FE). We add FE methods to control for unobserved firm-specific effects such as, for example, manager's ability or geographical 
characteristics, and also for the unbalanced nature of the sample. Second, we employ estimators that seek to correct for ME, which are IV two-stage least squares and GMM, and our proposed S-estimator where we model the joint interaction of Tobin's $q$ and the error term. For the second set of estimators, we use data in levels as well as the demeaned version of the estimators for controlling for $\mathrm{FE}^{5}$

The results for OLS and FE models are summarized in Table 2. These are the benchmark estimates. Table 3 collects the results for the standard IV estimator and Table 4 for the FE version of the IV estimator. The results obtained from our simultaneous estimator are collected in Tables 6-7, for the model in levels and demeaned data, respectively. All of the reported methods use different combinations of lags of the endogenous variables (Tobin's q) as instruments. In our model, these combinations of lags are interpreted as candidates to model the joint interaction between the endogenous variable and the error term. The results for different choices of lagged values of Tobin's $q$ assess the robustness of our procedure to such choice.

The OLS estimates show that both $q$ and $C F$ have positive coefficients that are statistically significant (see Table 2). In the OLS specification, we obtain a Tobin's $q$ coefficient of 0.0726 , and a cash flow coefficient of 0.0521 , which are likely to be biased. These results are also consistent with those found in the OLS related literature, in particular, Agca and Mozumdar (2016), and Almeida, Campello, and Galvao (2010). Next, we consider firmspecific FE. The results are also in Table 2. The estimate for Tobin's $q$ increases to 0.0809 and for cash flow decreases to 0.0432, both being statistically significant. These are, however, not statistically different from OLS.

\section{[TABLE 2 ABOUT HERE]}

\footnotetext{
${ }^{5}$ For the sake of presentation, we do not report the results for the GMM and Fixed Effects GMM cases. For both methods, the results are very similar to the IV counterpart estimators. The results for these methods are, nevertheless, avaiable from the authors upon request.
} 
We move our attention to models that correct for the measurement error in Tobin's q. First, we consider the IV estimates, which are represented by a two-stage least squares estimator in Table 3. We report the value of the parameter estimates associated to $q$ and $C F$ for different choices of instruments based on lags of $q_{t}$ and $q_{t}^{2}$ such that each estimator builds on the previous set of instruments added by one further lag of $q$ or $q^{2}$. The results in Table 3 highlight the role of adding more lags up to $q_{t-3}$. The parameter estimates are very similar across estimators yielding values oscillating about 0.0524 and 0.0515 for Tobin's $q$ and cash flow, respectively, for the IV estimator. Table 4 reports the estimates of the IV estimator that controls for fixed effects. The results of this exercise are very similar to those obtained for the previous IV case.

\section{[TABLES 3 TO 4 ABOUT HERE]}

Before presenting the results for the S-estimator, we assess the potential presence of correlation in the investment equation by implementing Arellano and Bond (1991) tests for autocorrelation. Table 5 reports the tests for autocorrelation of orders 1, 2 and 3 for the residuals of the OLS and IV models, and of the corresponding counterpart models accounting for the presence of fixed effects (FE and FE-IV). The evidence points to the presence of strong persistence in the error term even for the residuals of IV models, which signals persistence in measurement errors in Tobin's $q$ and, hence, provides evidence that invalidates the IV methods.

\section{[TABLE 5 ABOUT HERE]}

The presence of persistence in measurement errors, thus, motivates our proposed estimator. To provide further evidence on the suitability of our method for estimating the investment equation model we discuss the following example. Suppose we compute OLS 
residuals from Table 2 column OLS, i.e., $\widehat{\varepsilon}_{t}=y_{i t}-\left(\widehat{\alpha}_{O L S}+\widehat{\beta}_{O L S} q_{i t}+\widehat{\gamma}_{O L S} C F_{i t}\right)$. The evidence in the above paragraph determines that this would be correlated with the lags of Tobin's $q$. Left panel of Figure 1 shows that $q_{t-1}$ is correlated with both $q_{t}$ and OLS residuals. A visual inspection reveals that the graph has a clear negative slope in the direction given by Tobin's $q$ but it is also related to the OLS residuals. The right panel displays the quantity $\widehat{\varepsilon}_{t} \times q_{t}$ as a function of $q_{t-1}$. The plot reveals a positive correlation between the joint interaction of Tobin's $q$ and the OLS residual with the first lag of Tobin's $q$.

\section{[FIGURE 1 ABOUT HERE]}

We complete the section by presenting results for two different versions (one in levels and one with demeaned data using the within transformation) of the proposed S-estimator. The results are presented in Tables 6 and 7. The coefficients for both the Tobin's $q$ and $C F$ are statistically different from zero. In fact, the Tobin's $q$ coefficient is almost twice as large as the standard OLS estimate across models, and the cash flow coefficient is about $10 \%$ smaller than the corresponding OLS value. Thus, although the theory does not pin down the exact values that this coefficient should take, one could argue that an estimator that solves measurement error in the true $q^{*}$ in a standard investment equation should return a higher estimate for $\beta$ when compared with standard OLS estimates. This is so because the measurement error causes an attenuation bias on the estimate for this coefficient. On the contrary, the IV procedure returns estimates for Tobin's $q$ that do not satisfy this condition, although they are statistically significant. Further, the values of the parameter estimates are rather stable across exercises but the comparison of the estimates across models highlights the relevance of including $q_{t-1}$ and $q_{t-1}^{2}$ in the set of observables $Z$ compared to including $q_{t-2}$ and beyond. ${ }^{6}$ The analysis of the results for the S-estimator using demeaned variables

\footnotetext{
${ }^{6}$ The choice of an appropriate polynomial $\boldsymbol{Z}_{i t}$ is analogous to the IV approach of which consistency heavily relies on an appropriate selection of valid instruments. This empirical result highlights the importance of
} 
reported in Table 7 sheds similar findings to Table 6. The magnitudes of the parameter estimates for both Tobin's $q$ and firm's cash flows are, however, slightly higher. The role of $q_{t-2}$ and higher order lags are more relevant than in the version of the S-estimator from the data in levels.

\section{[TABLES 6 AND 7 ABOUT HERE]}

The empirical findings in Tables 6 and 7 suggest that the effect of Tobin's $q$ on the investment capital ratio is greater than that estimated by OLS and IV. These findings are in itself evidence that the S-estimator is doing a good job of capturing the true variation in investment opportunities. Low observed Tobin's $q$ coefficients have been noted in the literature as a diagnostic for the failure of the empirical investment model, however, the estimates obtained from our proposed method are significantly higher. Furthermore, the sensitivity of cash flow does not vanish after correcting for ME bias. This empirical observation is also noted in Agca and Mozumdar (2016) and challenges previous literature minimizing the role of cash flows in explaining the rate of investment. This interesting empirical finding is analyzed in more detail in the following section.

\subsubsection{The sensitivity of cash flow and financial constraints}

The literature on the influence of cash flow on investment is very controversial. In this empirical exercise, we separate the analysis into firms that are financially constrained and those that are not, and assess the sensitivity of investment ratio to cash flow in each case. We follow seminal contributions in the literature such as Almeida, Campello, and Weisbach (2004), Moyen (2004) and Hadlock and Pierce (2010) to characterize constrained and unconstrained

studying the optimal number of lags for this novel estimation method. We leave this study for future research. As a robustness check, we also considered in unreported exercises higher-order moments such as the cubes of the lags of $q$ but the results do not substantially change. 
firms. ${ }^{7}$ In particular, we discuss four alternative schemes to distinguish between constrained and unconstrained firms. The first two schemes are taken from Almeida, Campello, and Weisbach (2004). These authors propose five different schemes to distinguish between financially constrained and unconstrained firms but, for the sake of space and data availability reasons, we only focus on those schemes that are determined by the payout ratio and firms' asset size. For completeness, we reproduce here schemes 1 and 2.

Scheme 1: Firms are ranked based on their payout ratio and assigned to the financially constrained (unconstrained) group those firms in the bottom (top) three deciles of the annual payout distribution. The payout ratio is computed as the ratio of total distributions (dividends plus stock repurchases) to operating income. Financially constrained firms have lower payout ratios (see Fazzari, Hubbard, and Petersen (1988) and Almeida, Campello, and Weisbach (2004) for further motivation on this finding).

Scheme 2: Firms are ranked based on their asset size over the 1974 to 2010 period and assigned to the financially constrained (unconstrained) group those firms in the bottom (top) three deciles of the size distribution. The rankings are again performed on an annual basis. Small firms are typically young, less well known, and thus more vulnerable to capital market imperfections so they are identified as financially constrained as opposed to large firms that are identified as financially unconstrained.

We also propose a third scheme advocated in Moyen (2004) based on firms' dividends rather than on the payout ratios.

\footnotetext{
${ }^{7}$ There are other influential studies proposing indices to characterize firms in terms of financial conditions such as Kaplan and Zingales (1997) or Whited and Wu (2006), however, the nature of our database does not allow us to compute these indices. We, nevertheless, believe that the empirical exercise carried out below is quite comprehensive as it covers most of the distinctive features characterizing each of the different indices.
} 
Scheme 3: Firms are ranked based on dividends (sum of dividends on common and preferred stocks) over the 1974 to 2010 period and assigned to the financially constrained (unconstrained) group those firms in the bottom (top) three deciles of the dividend payment distribution. The rankings are again performed on an annual basis.

As a further robustness check, we also consider the classification of firms using the index proposed in Hadlock and Pierce (2010). ${ }^{8}$ This index is defined as a combination of firms' asset size and age; more specifically, the index is constructed as -0.737 Size +0.043 Size $^{2}-$ 0.040 Age.

Scheme 4: Firms are ranked based on the Hadlock and Pierce (2010) index computed over the 1974 to 2010 period. The financially constrained (unconstrained) group is comprised by those firms in the top (bottom) three deciles of the index distribution. The rankings are again performed on an annual basis. In contrast to the previous schemes, and due to the definition of the index, the constrained group is found at the top deciles of the distribution.

We proceed now to discuss the empirical findings obtained from running the investment equation separately for each group of firms.

Table 8 presents the estimates of the $q$ and $C F$ coefficients for Scheme 1 . This scheme classifies firms with high and low payout ratios as financially unconstrained and constrained, respectively. There are significant differences in the magnitude of the Tobin's $q$ parameter estimates across groups. In particular, the sensitivity of Tobin's $q$ to investment demand is several times higher for constrained firms than for unconstrained firms. In contrast, we observe a greater sensitivity of investment to firms' cash flows for unconstrained firms than for constrained firms. This result contrasts with the literature on investment that follows

\footnotetext{
${ }^{8}$ We are grateful to an anonymous referee for suggesting this analysis.
} 
from Fazzari, Hubbard, and Petersen (1988) and agrees with the findings obtained in Kaplan and Zingales (1997). The comparison among estimation methods also highlights important differences between the IV methodology and our proposed S-estimators. These differences are particularly large for the analysis of Tobin's $q$ for constrained firms. For example, the FEIV6 estimator for low payout ratios reports parameter estimates equal to 0.123, whereas the estimators S6 and SFE6 report values of 0.2243 and 0.2209, respectively.

\section{[TABLE 8 ABOUT HERE]}

Table 9 presents the estimates of the $q$ and $C F$ coefficients for Scheme 2. This scheme classifies large firms as financially unconstrained and small firms as financially constrained. The results reported in the table suggest a greater sensitivity of cash flows to investment for constrained than unconstrained firms. These results are in line with Fazzari, Hubbard, and Petersen (1988), Agca and Mozumdar (2016) and most of the empirical investment literature highlighting the differences between external and internal financing for determining investment demand.

\section{[TABLE 9 ABOUT HERE]}

The contradictory results obtained from comparing Table 8 and Table 9 suggest that the criteria used to define financial constraints can reflect different firms' features. To provide further empirical evidence on the effect of firms' cash flows as a function of financial constraints, we use the classification proposed in Scheme 3 based on dividend payments. The results reported in Table 10 provide empirical evidence similar to the analysis using payout ratios. Note, for example, the parameter estimates of the Tobin's $q$ coefficient. These findings are very supportive of the idea that cash flow of firms paying larger dividends have stronger predictive power for determining investment demand than low dividend firms' cash flows. 


\section{[TABLE 10 ABOUT HERE]}

As a further robustness check, we consider Scheme 4 based on the Hadlock and Pierce (2010) index that classifies firms as a function of asset size and age. The classification of firms as constrained and unconstrained according to this index is similar to the classification obtained in Scheme 2. Table 11 reports empirical results for the unconstrained and constrained firms according to this index that are consistent with the classification of firms in terms of asset size. In particular, the effect of firms' cash flows is higher (around 0.1357) for constrained firms than for unconstrained firms (0.077).

\section{[TABLE 11 ABOUT HERE]}

These empirical findings are robust across estimation methods but exhibit large parameter variability that challenges the validity of the different methods. To formally asses this, we compute in Table 12 the Arellano and Bond (1991) test for serial autocorrelation of the residuals obtained from the OLS and IV models, and the corresponding fixed effects counterpart models obtained from the within transformation. The results show overwhelming evidence of serial correlation in the residuals and shed important doubts on the validity of the IV methodology in this context. These results provide further empirical support to choosing the alternative family of simultaneous estimators proposed in this paper.

\section{[TABLE 12 ABOUT HERE]}

As a final separate exercise to empirically assess the relationship between investment demand, Tobin's $q$ and firms' cash flow, we study the effect of a credit supply shock on investment-cash flow sensitivities for groups of financially constrained firms. ${ }^{9}$ Recent literature focuses on an alternative method to measure the effect of liquidity on investment,

\footnotetext{
${ }^{9} \mathrm{We}$ are grateful to an anonymous referee for suggesting this analysis.
} 
which exploits financial shocks in a difference-in-differences framework (see, e.g., Lemmon and Roberts (2010), Almeida, andBruno Laranjeira, and Weisbenner (2011) and Duchin, Ozbas, and Sensoy (2010)). In this paper, we do not consider a difference-in-differences framework, but instead, compute the investment regression equation for two different periods separated by a structural break defined by the passage of the Financial Institutions Reform, Recovery, and Enforcement Act (FIRREA) of 1989, see Lemmon and Roberts (2010). The passage of FIRREA led to an immediate cessation of the $\$ 12$ billion annual flow of capital to speculative-grade firms from savings and loans, while simultaneously forcing a sell-off of all junk bond holdings. Thus, whereas the period before 1989 is characterized by the absence of credit and liquidity constraints, after 1989 financially constrained firms faced a potentially disrupting financing environment that could have led them to use more of the cash flows to finance investment.

As our database does not contain information on firms' bond ratings, we proxy firms' financial constraints using asset size and the payout ratio. ${ }^{10}$ Table 13 reports the estimates of the cash flow sensitivities and Tobin's $q$ to investment using the payout ratio (Scheme 1) as classification criteria. Table 14 shows the counterpart estimates before and after 1989 using firms' asset size (Scheme 2).

\section{[TABLES 13 AND 14 ABOUT HERE]}

The results corresponding to both firms' classifications are robust across estimation methods and reveal a decrease on the effect of firms' cash flows after 1989. These results provide further empirical evidence suggesting that the positive correlation between investment demand and firms' cash flows decreases in periods characterized by tighter financial conditions.

\footnotetext{
${ }^{10}$ For sake of space, we do not entertain constrained firms characterized by dividends and the HadlockPierce index. It is worth noting, though, the strong positive correlation between the classification of firms in terms of the payout ratio and dividends, and in terms of asset size and the Hadlock-Pierce index.
} 
This empirical finding is broadly consistent with the findings obtained from the analysis of payout ratios and firm dividends, and the conclusions in Kaplan and Zingales (1997).

\section{Conclusion}

This paper addresses the measurement error problem arising in investment equations relating firms' investment demand with Tobin's $q$ and cash flow. We have shown that the presence of serial correlation in the measurement error variable invalidates standard corrections based on IV methods. To solve the problem, we have proposed an alternative methodology that is based on modeling the interaction between the endogenous regressor (average Tobin's q) and the error term as a function of lags of the endogenous regressor. The solution yields a consistent and asymptotically normal estimator that works under serial correlation of the structural equation error term and allows one to make correct statistical inference.

An application to a panel of U.S. firms reveals stark differences between the novel estimator and existing competitors highlighting the relevance of Tobin's $q$ and firms' cash flow for explaining investment demand. More specifically, the S-estimator shows that the effect of these variables on predicting investment demand is greater than those estimated by the OLS and IV methodologies. These findings are in itself evidence that the S-estimator is doing a good job of capturing the true variation in investment opportunities.

The empirical analysis also contributes to the discussion on the differences of firms' cash flow on investment demand between financially constrained and unconstrained firms. We find mixed evidence on the effect of firms' cash flows on investment demand between financially constrained and unconstrained firms. More specifically, whereas we observe higher sensitivity to cash flows for financially constrained firms defined by smaller and younger firms, we find a similar finding for the group of unconstrained firms characterized by high payout ratios and

dividend payments. Nevertheless, the natural experiment consisting of studying the effect of 
a credit supply shock on the relationship between investment demand and firms' cash flow supports the view that cash flow has less predictive power under tighter financial conditions. 


\section{References}

Abel, A. B., And J. C. Eberly (1994): "A Unified Model of Investment Under Uncertainty," American Economic Review, 84, 1369-1384.

AgCA, S., And A. Mozumdar (2016): "Investment Cash Flow Sensitivity: Fact or Fiction?," forthcoming in the Journal of Financial and Quantitative Analysis.

Almeida, H., M. C. andBruno Laranjeira, and S. Weisbenner (2011): "Corporate Debt Maturity and the Real Effects of the 2007 Credit Crisis," Critical Finance Review, $1,3-58$.

Almeida, H., and M. Campello (2007): "Financial Constraints, Asset Tangibility and Corporate Investment," Review of Financial Studies, 20, 1429-1460.

Almeida, H., M. Campello, and A. Galvao (2010): "Measurement Errors in Investment Equations," Review of Financial Studies, 23, 3279-3328.

Almeida, H., M. Campello, and M. S. Weisbach (2004): "The Cash Flow Sensitivity of Cash," Journal of Finance, 59, 1777-1804.

Arellano, M., And S. Bond (1991): "Some Tests of Specification for Panel Data: Monte Carlo Evidence and an Application to Employment Equations," Review of Economic Studies, 58, 277-279.

Bernanke, B., And M. Gertler (1989): "Agency costs, net worth, and business fluctuations," American Economic Review, 79, 14-31.

Bertrand, M., and S. Mullainathan (2005): "Bidding for Oil and Gas Leases in the Gulf of Mexico: A Test of the Free Cash Flow Model?," mimeo, The University of Chicago and MIT. 
Bertrand, M., And A. Schoar (2003): "Managing with Style: The Effect of Managers on Firm Policies," Quarterly Journal of Economics, 118, 1169-1208.

Chen, X. (2007): "Large Sample Sieve Estimation of Semi-nonparametric Models," in Handbook of Econometrics, ed. by J. J. Heckman, and E. E. Leamer, vol. 6B. NorthHolland.

Cummins, J. G., K. A. Hasset, and S. D. Oliner (2006): "Investment Behavior, Observable Expectations, and Internal Funds," American Economic Review, 96, 796-810.

Duchin, R., O. Ozbas, And B. A. Sensoy (2010): "Costly external finance, corporate investment, and the subprime mortgage credit crisis," Journal of Financial Economics, $97,418-435$.

ERICKson, T., AND T. Whited (2000): "Measurement Error and the Relationship between Investment and Q," Journal of Political Economy, 108, 1027-1057.

Fazzari, S., R. G. Hubbard, and B. Petersen (1988): "Financing Constraints and Corporate Investment," Brooking Papers on Economic Activity, 1, 141-195.

HADlOCK, C. (1998): "Ownership, Liquidity, and Investment," RAND Journal of Economics, 29, 487-508.

Hadlock, C. J., And J. R. Pierce (2010): "New Evidence on Measuring Financial Constraints: Moving Beyond the KZ Index," Review of Financial Studies, 23, 1909-1940.

HAYASHI, F. (1982): "Tobin's Marginal q and Average q: A Neoclassical Interpretation," Econometrica, 50, 213-224.

Holmstrom, B., And J. Tirole (1998): "Private and public supply of liquidity," Journal of Political Economy, 106, 1-40. 
Hoshi, T., A. Kashyap, and D. Scharfstein (1991): "Corporate Structure, Liquidity, and Investment: Evidence from Japanese Industrial Groups," Quarterly Journal of Economics, 106, 33-60.

Kaplan, S., and L. Zingales (1997): "Do Financing Constraints Explain Why Investment Is Correlated with Cash Flow?," Quarterly Journal of Economics, 112, 169-215.

Kind, R., And R. Levine (1993): "Finance and growth: Schumpeter might be right," Quarterly Journal of Economics, 108, 717-737.

Kiyotaki, N., And J. Moore (1997): "Credit Cycles," Journal of Political Economy, 105, $211-248$.

Lamont, O. (1999): "Cash Flow and Investment: Evidence from Internal Capital Markets," The Journal of Finance, 52, 83-110.

Lemmon, M., and M. R. Roberts (2010): "The Response of Corporate Financing and Investment to Changes in the Supply of Credit," Journal of Financial and Quantitative Analysis, 45, 555-587.

Lewellen, J., And K. Lewellen (2014): "Investment and Cashflow: New Evidence," Journal of Financial and Quantitative Analysis, Forthcoming.

Modigliani, F., and M. Miller (1958): "The Cost of Capital, Corporation Finance and the Theory of Investment," American Economic Review, 48, 261-297.

Moyen, N. (2004): "Investment-Cash Flow Sensitivities: Constrained versus Unconstrained Firms," The Journal of Finance, 59, 2061-2092.

Pagan, A. (1984): "Econometric Issues in the Analysis of Regressions with Generated Regressors," International Economic Review, 25, 221-247. 
Poterba, J. (1988): "Financing Constraints and Corporate Investment: Comment," Brookings Papers on Economic Activity, 1, 200-204.

Shin, H., And R. Stulz (1998): "Are Internal Capital Markets Efficient?," Quarterly Journal of Economics, 113, 531-552.

Stein, J. (2003): "Agency Information and Corporate Investment," in Handbook of the Economics of Finance, ed. by M. Harris, and R. Stulz. Elsevier/North-Holland, Amsterdam.

Whited, T. M., And G. Wu (2006): "Financial Constraints Risk," Review of Financial Studies, 19, 531-559. 


\section{Appendix}

\section{A. Proof of the Theorems}

\section{Proof of Theorem 1}

We prove the result by showing that solutions to a system of equations are unique if and only if Assumption 1 (ii) holds. We first note that from Assumption 1 (i) $\mathrm{E}\left(\boldsymbol{x}_{1}^{\top} \epsilon\right)=0$ we have

$$
\mathrm{E}\left(\boldsymbol{x}_{1}^{\top} y\right)-\mathrm{E}\left(\boldsymbol{x}_{1}^{\top} \boldsymbol{x}_{1}\right) \boldsymbol{\theta}_{1}-\mathrm{E}\left(\boldsymbol{x}_{1}^{\top} q\right) \beta=0 .
$$

From Assumption 1 (iii) and the definition of $\boldsymbol{\theta}_{1}$ and $\boldsymbol{\theta}_{2}$, we also obtain

$$
\begin{aligned}
u & =q \epsilon-\boldsymbol{Z} \boldsymbol{\phi} \\
& =q\left(y-\boldsymbol{x}_{1} \boldsymbol{\theta}_{1}-q \beta\right)-\boldsymbol{Z} \boldsymbol{\phi} \\
& =q y-q \boldsymbol{x}_{1}\left(\mathrm{E}\left(\boldsymbol{x}_{1}^{\top} \boldsymbol{x}_{1}\right)^{-1} \mathrm{E}\left(\boldsymbol{x}_{1}^{\top} y\right)-\mathrm{E}\left(\boldsymbol{x}_{1}^{\top} \boldsymbol{x}_{1}\right)^{-1} \mathrm{E}\left(\boldsymbol{x}_{1}^{\top} q\right) \beta\right)-q^{2} \beta-\boldsymbol{Z} \boldsymbol{\phi} \\
& =q\left(y-\boldsymbol{x}_{1} \mathrm{E}\left(\boldsymbol{x}_{1}^{\top} \boldsymbol{x}_{1}\right)^{-1} \mathrm{E}\left(\boldsymbol{x}_{1}^{\top} y\right)\right)-q\left(q-\boldsymbol{x}_{1} \mathrm{E}\left(\boldsymbol{x}_{1}^{\top} \boldsymbol{x}_{1}\right)^{-1} \mathrm{E}\left(\boldsymbol{x}_{1}^{\top} q\right)\right) \beta-\boldsymbol{Z} \boldsymbol{\phi} \\
& =\tilde{y}-\tilde{\boldsymbol{x}} \boldsymbol{\theta}_{2} .
\end{aligned}
$$

Then from $\mathrm{E}\left(\tilde{\boldsymbol{x}}^{\top} u\right)=\mathrm{E}\left(\tilde{\boldsymbol{x}}^{\top}\left(\tilde{y}-\tilde{\boldsymbol{x}} \boldsymbol{\theta}_{2}\right)\right)=0$, we have

$$
\mathrm{E}\left(\tilde{\boldsymbol{x}}^{\top} \tilde{y}\right)-\mathrm{E}\left(\tilde{\boldsymbol{x}}^{\top} \tilde{\boldsymbol{x}}\right) \boldsymbol{\theta}_{2}=0 .
$$

The conclusion immediately follows by equations (10)-(11) and Assumption 1 (ii). Q.E.D.

\section{Proof of Proposition 1}

We first recall that $\epsilon_{i t} \equiv \eta_{i t}-\beta e_{i t}$ such that

$$
\begin{aligned}
q_{i t} \epsilon_{i t} & =q_{i t}\left(\eta_{i t}-\beta e_{i t}\right) \\
& =q_{i t} \eta_{i t}-\beta q_{i t} e_{i t}+\mathrm{E}\left[\beta q_{i t} e_{i t} \mid \boldsymbol{z}_{i t}\right]-\mathrm{E}\left[\beta q_{i t} e_{i t} \mid \boldsymbol{z}_{i t}\right] \\
& =g\left(\boldsymbol{z}_{i t}\right)+u_{i t}
\end{aligned}
$$


where $u_{i t} \equiv q_{i t} \eta_{i t}-\beta q_{i t} e_{i t}-\mathrm{E}\left[\beta q_{i t} e_{i t} \mid \boldsymbol{z}_{i t}\right]$, and $g\left(\boldsymbol{z}_{i t}\right) \equiv \mathrm{E}\left[\beta q_{i t} e_{i t} \mid \boldsymbol{z}_{i t}\right] \neq 0$ because $q_{i t}^{*}$ is autocorrelated. In addition, by assumption $g\left(\boldsymbol{z}_{i t}\right)$ can be approximated by a polynomial of order $m$, hence we have that $q_{i t} \epsilon_{i t}=\boldsymbol{Z}_{i t} \boldsymbol{\phi}+u_{i t}$.

Now, from the above equation, it remains to show that $\mathrm{E}\left[\tilde{\boldsymbol{x}}_{i t}^{\top} u_{i t}\right]=0$ where $\tilde{\boldsymbol{x}}_{i t}=\left[q_{i t}^{2}, \boldsymbol{Z}_{i t}\right]$ with $\boldsymbol{Z}_{i t}=\left[1, q_{i t-1}, q_{i t-1}^{2}, \ldots, q_{i t-1}^{m}\right]$. We do this by proving $\mathrm{E}\left[u_{i t} \mid q_{i t}, \boldsymbol{z}_{i t}\right]=0$ because this implies $\mathrm{E}\left[\tilde{\boldsymbol{x}}_{i t}^{\top} u_{i t}\right]=0$. From the definition of $u_{i t}$ above

$$
\begin{aligned}
\mathrm{E}\left[u_{i t} \mid q_{i t}, \boldsymbol{z}_{i t}\right] & \equiv \mathrm{E}\left[q_{i t} \eta_{i t}-\beta q_{i t} e_{i t}-\mathrm{E}\left[\beta q_{i t} e_{i t} \mid \boldsymbol{z}_{i t}\right] \mid q_{i t}, \boldsymbol{z}_{i t}\right] \\
& =q_{i t} \mathrm{E}\left[\eta_{i t} \mid q_{i t}, \boldsymbol{z}_{i t}\right]-\mathrm{E}\left[\beta q_{i t} e_{i t} \mid q_{i t}, \boldsymbol{z}_{i t}\right]-\mathrm{E}\left[\beta q_{i t} e_{i t} \mid \boldsymbol{z}_{i t}\right] \\
& =q_{i t} \mathrm{E}\left[\eta_{i t} \mid q_{i t}, \boldsymbol{z}_{i t}\right]-\beta q_{i t}\left(\mathrm{E}\left[e_{i t} \mid q_{i t}, \boldsymbol{z}_{i t}\right]-\mathrm{E}\left[e_{i t} \mid \boldsymbol{z}_{i t}\right]\right) \\
& =0
\end{aligned}
$$

since $\mathrm{E}\left[\eta_{i t} \mid q_{i t}, \boldsymbol{z}_{i t}\right]=0$ by the mean-zero white noise process of $\eta_{i t}$, and since $\mathrm{E}\left[e_{i t} \mid q_{i t}, \boldsymbol{z}_{i t}\right]=$ $\mathrm{E}\left[e_{i t} \mid \boldsymbol{z}_{i t}\right]$ by the fact that by Assumption $2 e_{i t}=h\left(e_{i t-1}, q_{i t-1}^{*}\right)$ implies $e_{i t}=\tilde{h}\left(q_{i t-1}\right)$ for a measurable function $\tilde{h}(\cdot)$. This completes the proof. Q.E.D.

\section{Proof of Theorem 2}

We show the asymptotic distribution of the proposed estimator by taking into account the problem of the generated variables. This is an extension of the problem of the generated regressor in Pagan (1984). Recall that

$\widehat{\boldsymbol{\theta}}_{1}=\left(\frac{1}{n} \sum_{i=1}^{n} \sum_{t=1}^{T} \boldsymbol{x}_{1 i t}^{\top} \boldsymbol{x}_{1 i t}\right)^{-1}\left(\frac{1}{n} \sum_{i=1}^{n} \sum_{t=1}^{T} \boldsymbol{x}_{1 i t}^{\top} y_{i t}\right)-\left(\frac{1}{n} \sum_{i=1}^{n} \sum_{t=1}^{T} \boldsymbol{x}_{1 i t}^{\top} \boldsymbol{x}_{1 i t}\right)^{-1}\left(\frac{1}{n} \sum_{i=1}^{n} \sum_{t=1}^{T} \boldsymbol{x}_{1 i t}^{\top} q_{i t}\right) \widehat{\beta}$

and

$$
\widehat{\boldsymbol{\theta}_{2}}=\left(\frac{1}{n} \sum_{i=1}^{n} \sum_{t=1}^{T} \widehat{\boldsymbol{x}}_{i t}^{\top} \widehat{\boldsymbol{x}}_{i t}\right)^{-1}\left(\frac{1}{n} \sum_{i=1}^{n} \sum_{t=1}^{T} \widehat{\boldsymbol{x}}_{i t}^{\top} \widehat{y}_{i t}\right) .
$$

Also recall that $\tilde{\boldsymbol{x}} \equiv\left[q\left(q-\boldsymbol{x}_{1} \delta_{q}\right), \boldsymbol{Z}\right]$ with $\delta_{q} \equiv \mathrm{E}\left(\boldsymbol{x}_{1}^{\top} \boldsymbol{x}_{1}\right)^{-1} \mathrm{E}\left(\boldsymbol{x}_{1}^{\top} q\right)$, and $\tilde{y} \equiv q\left(y-\boldsymbol{x}_{1} \delta_{y}\right)$ with $\delta_{y} \equiv \mathrm{E}\left(\boldsymbol{x}_{1}^{\top} \boldsymbol{x}_{1}\right)^{-1} \mathrm{E}\left(\boldsymbol{x}_{1}^{\top} y\right)$. In addition, define the sample analogues $\widehat{\boldsymbol{x}} \equiv\left[q\left(q-\boldsymbol{x}_{1} \widehat{\delta_{q}}\right), \boldsymbol{Z}\right]$ 
with $\widehat{\delta}_{q} \equiv\left(\frac{1}{n} \sum_{i=1}^{n} \sum_{t=1}^{T} \boldsymbol{x}_{1 i t}^{\top} \boldsymbol{x}_{1 i t}\right)^{-1}\left(\frac{1}{n} \sum_{i=1}^{n} \sum_{t=1}^{T} \boldsymbol{x}_{1 i t}^{\top} q_{i t}\right)$, and $\widehat{y} \equiv q\left(y-\boldsymbol{x}_{1} \widehat{\delta}_{y}\right)$ with $\widehat{\delta}_{y} \equiv$ $\left(\frac{1}{n} \sum_{i=1}^{n} \sum_{t=1}^{T} \boldsymbol{x}_{1 i t}^{\top} \boldsymbol{x}_{1 i t}\right)^{-1}\left(\frac{1}{n} \sum_{i=1}^{n} \sum_{t=1}^{T} \boldsymbol{x}_{1 i t}^{\top} y_{i t}\right)$.

We first show the asymptotic properties of $\widehat{\boldsymbol{\theta}}_{2}$. We note that since $\tilde{y}_{i t}=\tilde{\boldsymbol{x}}_{i t} \boldsymbol{\theta}_{2}+u_{i t}$, we have

$$
\widehat{y}_{i t}=\widehat{\boldsymbol{x}}_{i t} \boldsymbol{\theta}_{2}+u_{i t}-\left(\widehat{\boldsymbol{x}}_{i t}-\tilde{\boldsymbol{x}}_{i t}\right) \boldsymbol{\theta}_{2}+\left(\widehat{y}_{i t}-\tilde{y}_{i t}\right) .
$$

By plugging the equation above into the definition of $\widehat{\boldsymbol{\theta}}_{2}$, we obtain

$$
\widehat{\boldsymbol{\theta}}_{2}=\boldsymbol{\theta}_{2}+\left(\frac{1}{n} \sum_{i=1}^{n} \sum_{t=1}^{T} \widehat{\boldsymbol{x}}_{i t}^{\top} \widehat{\boldsymbol{x}}_{i t}\right)^{-1}\left(\frac{1}{n} \sum_{i=1}^{n} \sum_{t=1}^{T} \widehat{\boldsymbol{x}}_{i t}^{\top}\left(u_{i t}-\left(\widehat{\boldsymbol{x}}_{i t}-\tilde{\boldsymbol{x}}_{i t}\right) \boldsymbol{\theta}_{2}+\left(\widehat{y}_{i t}-\tilde{y}_{i t}\right)\right)\right),
$$

so that

$$
\begin{aligned}
\sqrt{n}\left(\widehat{\boldsymbol{\theta}}_{2}-\boldsymbol{\theta}_{2}\right) & =\widehat{Q}^{-1} \sqrt{n} \frac{1}{n} \sum_{i=1}^{n} \sum_{t=1}^{T} \widehat{\boldsymbol{x}}_{i t}^{\top}\left(u_{i t}-\left(\widehat{\boldsymbol{x}}_{i t}-\tilde{\boldsymbol{x}}_{i t}\right) \boldsymbol{\theta}_{2}+\left(\widehat{y}_{i t}-\tilde{y}_{i t}\right)\right) \\
& =: \widehat{Q}^{-1}\left(A_{1}-A_{2}+A_{3}\right)
\end{aligned}
$$

with $\widehat{Q} \equiv \frac{1}{n} \sum_{i=1}^{n} \sum_{t=1}^{T} \widehat{\boldsymbol{x}}_{i t}^{\top} \widehat{\boldsymbol{x}}_{i t}$, where $A_{1} \equiv \sqrt{n} \frac{1}{n} \sum_{i=1}^{n} \sum_{t=1}^{T} \widehat{\boldsymbol{x}}_{i t}^{\top} u_{i t}, A_{2} \equiv \sqrt{n} \frac{1}{n} \sum_{i=1}^{n} \sum_{t=1}^{T} \widehat{\boldsymbol{x}}_{i t}^{\top}\left(\widehat{\boldsymbol{x}}_{i t}-\right.$ $\left.\tilde{\boldsymbol{x}}_{i t}\right) \boldsymbol{\theta}_{2}$, and $A_{3} \equiv \sqrt{n} \frac{1}{n} \sum_{i=1}^{n} \sum_{t=1}^{T} \widehat{\boldsymbol{x}}_{i t}^{\top}\left(\widehat{y}_{i t}-\tilde{y}_{i t}\right)$. We note that

$$
\widehat{Q} \equiv \frac{1}{n} \sum_{i=1}^{n} \sum_{t=1}^{T} \widehat{\boldsymbol{x}}_{i t}^{\top} \widehat{\boldsymbol{x}}_{i t} \stackrel{p}{\rightarrow} \mathrm{E}\left(\tilde{\boldsymbol{x}}_{i t}^{\top} \tilde{\boldsymbol{x}}_{i t}\right) \equiv Q
$$

by Slutsky theorem and law of large numbers (LLN). We also note that by a Taylor-series expansion,

$$
A_{1}=\sqrt{n} \frac{1}{n} \sum_{i=1}^{n} \sum_{t=1}^{T} \tilde{\boldsymbol{x}}_{i t}^{\top} u_{i t}+\left[\frac{1}{n} \sum_{i=1}^{n} \sum_{t=1}^{T} \nabla_{\delta_{q}} \tilde{\boldsymbol{x}}_{i t}^{\top} u_{i t}\right] \sqrt{n}\left(\widehat{\delta}_{q}-\delta_{q}\right)+o_{p}(1),
$$

with $\nabla_{\delta_{q}} \tilde{\boldsymbol{x}}_{i t}=\left[-q \boldsymbol{x}_{1}, \mathbf{0}_{k \times 1}^{\top}\right]$. Since $\mathrm{E}\left(u_{i t} \mid \tilde{\boldsymbol{x}}_{i t}\right)=0$, we have $\mathrm{E}\left(\nabla_{\delta_{q}} \tilde{\boldsymbol{x}}_{i t}^{\top} u_{i t}\right)=0$. Thus, we obtain $\frac{1}{n} \sum_{i=1}^{n} \sum_{t=1}^{T} \nabla_{\delta_{q}} \tilde{\boldsymbol{x}}_{i t}^{\top} u_{i t}=o_{p}(1)$. Since $\sqrt{n}\left(\widehat{\delta}_{q}-\delta_{q}\right)=O_{p}(1)$, it follows that

$$
A_{1}=\sqrt{n} \frac{1}{n} \sum_{i=1}^{n} \sum_{t=1}^{T} \tilde{\boldsymbol{x}}_{i t}^{\top} u_{i t}+o_{p}(1)
$$


By a similar argument, we have that

$$
A_{2}=\left[\frac{1}{n} \sum_{i=1}^{n} \sum_{t=1}^{T} \tilde{\boldsymbol{x}}_{i t}^{\top} \nabla_{\delta_{q}} \tilde{\boldsymbol{x}}_{i t} \boldsymbol{\theta}_{2}\right] \sqrt{n}\left(\widehat{\delta}_{q}-\delta_{q}\right)+o_{p}(1)=G \sqrt{n}\left(\widehat{\delta}_{q}-\delta_{q}\right)+o_{p}(1)
$$

with $G=\mathrm{E}\left[\tilde{\boldsymbol{x}}_{i t}^{\top} \nabla_{\delta_{q}} \tilde{\boldsymbol{x}}_{i t} \boldsymbol{\theta}_{2}\right]$. Since $\widehat{\delta}_{q} \equiv\left(\frac{1}{n} \sum_{i=1}^{n} \sum_{t=1}^{T} \boldsymbol{x}_{1 i t}^{\top} \boldsymbol{x}_{1 i t}\right)^{-1}\left(\frac{1}{n} \sum_{i=1}^{n} \sum_{t=1}^{T} \boldsymbol{x}_{1 i t}^{\top} q_{i t}\right)$ and $\delta_{q} \equiv \mathrm{E}\left(\boldsymbol{x}_{1}^{\top} \boldsymbol{x}_{1}\right)^{-1} \mathrm{E}\left(\boldsymbol{x}_{1}^{\top} q\right), A_{2}$ can be rewritten as follows,

$$
A_{2}=G \sqrt{n} \sum_{i=1}^{n} \sum_{t=1}^{T} r_{i t}\left(\delta_{q}\right)+o_{p}(1)
$$

with $r_{i t}\left(\delta_{q}\right)=\left(\frac{1}{n} \sum_{i=1}^{n} \sum_{t=1}^{T} \boldsymbol{x}_{1 i t}^{\top} \boldsymbol{x}_{1 i t}\right)^{-1}\left(\boldsymbol{x}_{1 i t}^{\top}\left(q_{i t}-\boldsymbol{x}_{1 i t} \delta_{q}\right)\right)$ and $\mathrm{E}\left[r_{i t}\left(\delta_{q}\right)\right]=0$ by the law of iterated expectations (LIE). Similarly, we obtain

$$
A_{3}=\left[\frac{1}{n} \sum_{i=1}^{n} \sum_{t=1}^{T} \tilde{\boldsymbol{x}}_{i t}^{\top} \nabla_{\delta_{y}} \tilde{y}_{i t}\right] \sqrt{n}\left(\widehat{\delta_{y}}-\delta_{y}\right)+o_{p}(1)=H \sqrt{n}\left(\widehat{\delta_{y}}-\delta_{y}\right)+o_{p}(1),
$$

with $\nabla_{\delta_{y}} \tilde{y}_{i t}=-q \boldsymbol{x}_{1}$ and $H=\mathrm{E}\left[\tilde{\boldsymbol{x}}_{i t}^{\top} \nabla_{\delta_{y}} \tilde{y}_{i t}\right]$. Since $\widehat{\delta}_{y} \equiv\left(\frac{1}{n} \sum_{i=1}^{n} \sum_{t=1}^{T} \boldsymbol{x}_{1 i t}^{\top} \boldsymbol{x}_{1 i t}\right)^{-1}\left(\frac{1}{n} \sum_{i=1}^{n} \sum_{t=1}^{T} \boldsymbol{x}_{1 i t}^{\top} y_{i t}\right)$ and $\delta_{y} \equiv \mathrm{E}\left(\boldsymbol{x}_{1}^{\top} \boldsymbol{x}_{1}\right)^{-1} \mathrm{E}\left(\boldsymbol{x}_{1}^{\top} y\right), A_{3}$ can be rewritten as follows,

$$
A_{3}=H \sqrt{n} \sum_{i=1}^{n} \sum_{t=1}^{T} s_{i t}\left(\delta_{y}\right)+o_{p}(1)
$$

with $s_{i t}\left(\delta_{y}\right)=\left(\frac{1}{n} \sum_{i=1}^{n} \sum_{t=1}^{T} \boldsymbol{x}_{1 i t}^{\top} \boldsymbol{x}_{1 i t}\right)^{-1}\left(\boldsymbol{x}_{1 i t}^{\top}\left(y_{i t}-\boldsymbol{x}_{1 i t} \delta_{y}\right)\right)$, and $\mathrm{E}\left[s_{i t}\left(\delta_{y}\right)\right]=0$ by LIE.

By plugging equations (13)-(16) into (12), we have

$$
\sqrt{n}\left(\widehat{\boldsymbol{\theta}}_{2}-\boldsymbol{\theta}_{2}\right)=Q^{-1}\left\{\sqrt{n} \frac{1}{n} \sum_{i=1}^{n} \sum_{t=1}^{T}\left[\tilde{\boldsymbol{x}}_{i t}^{\top} u_{i t}-G r_{i t}\left(\delta_{q}\right)+H s_{i t}\left(\delta_{y}\right)\right]\right\}+o_{p}(1) .
$$

As a result, we show the consistency of $\widehat{\boldsymbol{\theta}_{2}}$ :

$$
\widehat{\boldsymbol{\theta}_{2}} \stackrel{p}{\rightarrow} \boldsymbol{\theta}_{2}+Q^{-1} \cdot 0=\boldsymbol{\theta}_{2}
$$

To show the asymptotic normality, we have that

$$
\sqrt{n}\left(\widehat{\boldsymbol{\theta}_{2}}-\boldsymbol{\theta}_{2}\right) \stackrel{d}{\rightarrow} Q^{-1} N(0, M) \equiv N\left(0, Q^{-1} M Q^{-1}\right)
$$


with $M=\operatorname{Var}\left(\tilde{\boldsymbol{x}}_{i t}^{\top} u_{i t}-G r_{i t}\left(\delta_{q}\right)+H s_{i t}\left(\delta_{y}\right)\right)$, by the Lindeberg-Lévy central limit theorem.

We now show the asymptotic properties of $\widehat{\boldsymbol{\theta}}_{1}$. We note that

$$
\begin{aligned}
\widehat{\boldsymbol{\theta}}_{1} & =\left(\frac{1}{n} \sum_{i=1}^{n} \sum_{t=1}^{T} \boldsymbol{x}_{1 i t}^{\top} \boldsymbol{x}_{1 i t}\right)^{-1}\left(\frac{1}{n} \sum_{i=1}^{n} \sum_{t=1}^{T} \boldsymbol{x}_{1 i t}\left(\boldsymbol{x}_{1 i t} \boldsymbol{\theta}_{1}+q_{i t} \beta+\epsilon\right)\right) \\
& -\left(\frac{1}{n} \sum_{i=1}^{n} \sum_{t=1}^{T} \boldsymbol{x}_{1 i t}^{\top} \boldsymbol{x}_{1 i t}\right)^{-1}\left(\frac{1}{n} \sum_{i=1}^{n} \sum_{t=1}^{T} \boldsymbol{x}_{1 i t} q_{i t}\right) \widehat{\beta} \\
& =\boldsymbol{\theta}_{1}-\left(\frac{1}{n} \sum_{i=1}^{n} \sum_{t=1}^{T} \boldsymbol{x}_{1 i t}^{\top} \boldsymbol{x}_{1 i t}\right)^{-1}\left(\frac{1}{n} \sum_{i=1}^{n} \sum_{t=1}^{T} \boldsymbol{x}_{1 i t}^{\top} q_{i t}\right)(\widehat{\beta}-\beta)+o_{p}(1) .
\end{aligned}
$$

By LLN, we have

$$
\begin{aligned}
& \widehat{\boldsymbol{C}}_{1} \equiv \frac{1}{n} \sum_{i=1}^{n} \sum_{t=1}^{T} \boldsymbol{x}_{1 i t}^{\top} \boldsymbol{x}_{1 i t} \stackrel{p}{\rightarrow} \mathrm{E}\left(\boldsymbol{x}_{1 i t}^{\top} \boldsymbol{x}_{1 i t}\right) \equiv \boldsymbol{C}_{1}, \\
& \widehat{C}_{2} \equiv \frac{1}{n} \sum_{i=1}^{n} \sum_{t=1}^{T} \boldsymbol{x}_{1 i t}^{\top} q_{i t} \stackrel{p}{\rightarrow} \mathrm{E}\left(\boldsymbol{x}_{1 i t}^{\top} q_{i t}\right) \equiv C_{2},
\end{aligned}
$$

so that we show the consistency of $\widehat{\boldsymbol{\theta}}_{1}$ :

$$
\widehat{\boldsymbol{\theta}}_{1} \stackrel{p}{\rightarrow} \boldsymbol{\theta}_{1}-\boldsymbol{C}_{1}^{-1} C_{2} Q_{\beta}^{-1} \cdot 0=\boldsymbol{\theta}_{1}
$$

where $Q_{\beta}$ is the element in the $Q$ matrix that corresponds to the estimation of $\beta$. To show the asymptotic normality, we note that

$$
\sqrt{n}\left(\widehat{\boldsymbol{\theta}}_{1}-\boldsymbol{\theta}_{1}\right)=-\left(\frac{1}{n} \sum_{i=1}^{n} \sum_{t=1}^{T} \boldsymbol{x}_{1 i t}^{\top} \boldsymbol{x}_{1 i t}\right)^{-1}\left(\frac{1}{n} \sum_{i=1}^{n} \sum_{t=1}^{T} \boldsymbol{x}_{1 i t}^{\top} q_{i t}\right) \sqrt{n}(\widehat{\beta}-\beta) .
$$

Then, we get

$$
\sqrt{n}\left(\widehat{\boldsymbol{\theta}}_{1}-\boldsymbol{\theta}_{1}\right) \stackrel{d}{\rightarrow} \boldsymbol{C}_{1}^{-1} C_{2} N\left(0, V_{\widehat{\beta}}\right) \equiv N\left(0, \boldsymbol{C}_{1}^{-1} C_{2} V_{\widehat{\beta}} C_{2}^{\top} \boldsymbol{C}_{1}^{-1}\right)
$$

where $V_{\widehat{\beta}}$ is the variance of $\widehat{\beta}$. Q.E.D. 


\section{B. Inconsistency of IV estimator in the presence of serial persistence}

Consider, for instance, autoregressive models of order $1(\mathrm{AR}(1))$ for driving the marginal Tobin's $q$ :

$$
q_{i t}^{*}=\rho^{q} q_{i t-1}^{*}+w_{i t}^{q}
$$

where $\left|\rho^{q}\right|<1$ and $w_{i t}^{q}$ is $i . i . d$. and zero-mean process, and the measurement errors

$$
e_{i t}=h\left(e_{i t-1}, q_{i t-1}^{*}\right)
$$

as stated in Proposition $1 .^{11}$

From equation (3), the endogenous variable $q_{i t}$ can be rewritten as:

$$
\begin{aligned}
q_{i t} & =q_{i t}^{*}+e_{i t} \\
& =\rho^{q} q_{i t-1}^{*}+w_{i t}^{q}+e_{i t} \\
& =\rho^{q} q_{i t-1}+w_{i t}^{q}+h\left(e_{i t-1}, q_{i t-1}^{*}\right) .
\end{aligned}
$$

As a result, $q_{i t}$ is correlated with $q_{i t-1}$ so that $q_{i t-1}$ satisfies the instrument relevance condition. Namely, from equation (19), $q_{i t-1}$ is

$$
q_{i t-1}=\rho^{q} q_{i t-2}+w_{i t-1}^{q}+h\left(e_{i t-2}, q_{i t-2}^{*}\right) .
$$

If $\left\{q_{i t-2}, w_{i t-1}^{q}, q_{i t-2}^{*}, e_{i t-2}\right\}$ are uncorrelated with $\epsilon_{i t} \equiv \eta_{i t}-\beta e_{i t}$, the variable $q_{i t-1}$ satisfies the instrument exogeneity condition. Then, IV methods which employ $q_{i t-1}$ as an instrument produce consistent estimators of $\beta$ and $\gamma$. We note that higher-order lags of $q_{i t}$ also satisfy the exogeneity condition and, hence, can be also used as IV.

However, in practice, it is highly likely that current-period measurement error is correlated with the first-order or higher-order lags of the measurement error. This is the case if $\lambda_{i t}$

\footnotetext{
${ }^{11}$ There is no constant term in the process for $q_{i t}^{*}$ without loss of generality.
} 
or $\nu_{i t}$ exhibit some persistence. For example, consider the process of the measurement errors as in equation (18). The measurement errors are persistent in the sense that the last-period measurement error $\left(e_{i t-1}\right)$ affects the current-period $e_{i t}$. In this case, the instrument exogeneity condition is no longer valid because the instrument $q_{i t-1}=\rho^{q} q_{i t-2}+w_{i t-1}^{q}+h\left(e_{i t-2}, q_{i t-2}^{*}\right)$ is correlated with the error term,

$$
\epsilon_{i t} \equiv \eta_{i t}-\beta e_{i t}=\eta_{i t}-\beta h\left(e_{i t-1}, q_{i t-1}^{*}\right)
$$

through the lag of Tobin's $q\left(q_{i t-1}^{*}\right)$ and the lag of the measurement error $\left(e_{i t-1}\right)$. As a result, the IV approach proposed by Almeida, Campello, and Galvao (2010) also fails to obtain consistent parameter estimates.

This is partly addressed in the study carried out by Agca and Mozumdar (2016) by including longer lags of the instruments in the dynamic GMM approaches employed by Cummins, Hasset, and Oliner (2006) and Almeida, Campello, and Galvao (2010). However, the dynamic GMM approaches still fail to work if the measurement errors are persistent. For instance, if one assumes, instead, the second-order lag of the average Tobin's $q$ as instrument, $q_{i t-2}=\rho^{q} q_{i t-3}+w_{i t-2}^{q}+h\left(e_{i t-3}, q_{i t-3}^{*}\right)$, then, from equation (20), we have

$$
\epsilon_{i t}=\eta_{i t}-\beta h\left(e_{i t-1}, q_{i t-1}^{*}\right)=\eta_{i t}-\beta h\left(h\left(e_{i t-2}, q_{i t-2}^{*}\right), q_{i t-1}^{*}\right) .
$$

This algebra reveals that the IV is still correlated with the regression error term $\epsilon_{i t}$ through $q_{i t-2}^{*}$ and $e_{i t-2}$. In fact, the dynamic GMM approach is more efficient in that it provides smaller variance of the estimator by imposing a proper weighting matrix when the error term is heteroscedastic and autocorrelated. However, the estimator is inconsistent if the IV are correlated with the error term. Thus, employing higher-order lags of the IV and imposing a proper weighting matrix are not sufficient conditions to control for measurement errors in the average Tobin's $q$. 
Table 1: Investment model. Descriptive statistics

\begin{tabular}{cccccc}
\hline Variable & Mean & Std. Dev. & Min & Max & Obs \\
\hline Investment & 0.2070 & 0.1465 & 0.0000 & 8.5031 & 32698 \\
$q$ & 0.9295 & 0.4565 & 0.1786 & 22.7962 & 32698 \\
$C F$ & 0.3512 & 0.6666 & -83.0667 & 17.9674 & 32698 \\
\hline
\end{tabular}

Notes: Data from COMPUSTAT, 1974 to 2010. The sample consists of manufacturing firms with fixed capital of more than $\$ 5$ million (with 1976 as the base year for the cpi), and the sample firms have growth of less than $100 \%$ in both assets and sales. Observations with at least 3 lags.

Table 2: Investment model. Least-squares models

\begin{tabular}{lcc}
\hline VARIABLES & OLS & FE \\
\hline & & \\
& $0.0725^{* * *}$ & $0.0809^{* * *}$ \\
$C F$ & $(0.0089)$ & $(0.0078)$ \\
& $0.0521^{* * *}$ & $0.0432^{* * *}$ \\
Constant & $(0.0153)$ & $(0.0122)$ \\
& $0.1213^{* * *}$ & $0.1167^{* * *}$ \\
Observations & $(0.0047)$ & $(0.0059)$ \\
R-squared & 32,698 & 32,698 \\
Number of firms & 0.188 & 0.187 \\
\hline
\end{tabular}

Notes: Standard errors in parentheses. For OLS and FE we use cluster-robust standard errors by firm. ${ }^{* * *} \mathrm{p}<0.01,{ }^{* *} \mathrm{p}<0.05,{ }^{*} \mathrm{p}<0.1$. 
Table 3: Instrumental variables approach

\begin{tabular}{|c|c|c|c|c|c|c|}
\hline Second stage & IV1 & IV2 & IV3 & IV4 & IV5 & IV6 \\
\hline$q$ & $\begin{array}{c}0.0463^{* * *} \\
(0.0058)\end{array}$ & $\begin{array}{c}0.0520^{* * *} \\
(0.0062)\end{array}$ & $\begin{array}{c}0.0529^{* * *} \\
(0.0062)\end{array}$ & $\begin{array}{c}0.0529^{* * *} \\
(0.0062)\end{array}$ & $\begin{array}{c}0.0524^{* * *} \\
(0.0062)\end{array}$ & $\begin{array}{c}0.0524^{* * *} \\
(0.0062)\end{array}$ \\
\hline$C F$ & $\begin{array}{c}0.0513^{* * *} \\
(0.0183)\end{array}$ & $\begin{array}{c}0.0514^{* * * *} \\
(0.0176)\end{array}$ & $\begin{array}{c}0.0515^{* * *} \\
(0.0175)\end{array}$ & $\begin{array}{c}0.0515^{* * *} \\
(0.0175)\end{array}$ & $\begin{array}{c}0.0515^{* * *} \\
(0.0176)\end{array}$ & $\begin{array}{c}0.0515^{* * *} \\
(0.0176)\end{array}$ \\
\hline Constant & $\begin{array}{c}0.146^{* * *} \\
(0.0047)\end{array}$ & $\begin{array}{c}0.141^{* * *} \\
(0.0042)\end{array}$ & $\begin{array}{c}0.140^{* * *} \\
(0.0042)\end{array}$ & $\begin{array}{c}0.140^{* * *} \\
(0.0042)\end{array}$ & $\begin{array}{c}0.140^{* * *} \\
(0.0042)\end{array}$ & $\begin{array}{c}0.140^{* * *} \\
(0.0042)\end{array}$ \\
\hline Observations & 32,698 & 32,698 & 32,698 & 32,698 & 32,698 & 32,698 \\
\hline R-squared & 0.095 & 0.098 & 0.098 & 0.098 & 0.098 & 0.098 \\
\hline First stage & IV1 & IV2 & IV3 & IV4 & IV5 & IV6 \\
\hline$C F$ & $\begin{array}{c}-0.114 \\
(0.0713)\end{array}$ & $\begin{array}{c}-0.128^{*} \\
(0.0692)\end{array}$ & $\begin{array}{c}-0.129^{*} \\
(0.0683)\end{array}$ & $\begin{array}{l}-0.129^{*} \\
(0.0683)\end{array}$ & $\begin{array}{l}-0.129^{*} \\
(0.0684)\end{array}$ & $\begin{array}{l}-0.129^{*} \\
(0.0684)\end{array}$ \\
\hline$q_{t-1}$ & $\begin{array}{c}0.618^{* * *} \\
(0.0190)\end{array}$ & $\begin{array}{c}0.826^{* * *} \\
(0.0440)\end{array}$ & $\begin{array}{c}0.876^{\text {*** }} \\
(0.0323)\end{array}$ & $\begin{array}{c}0.867^{* * *} * \\
(0.0585)\end{array}$ & $\begin{array}{c}0.877^{* * *} \\
(0.0572)\end{array}$ & $\begin{array}{c}0.877^{* * *} \\
(0.0569)\end{array}$ \\
\hline$q_{t-1}^{2}$ & & $\begin{array}{c}-0.0251^{* * *} * \\
(0.0054)\end{array}$ & $\begin{array}{c}-0.0261^{* * *} \\
(0.0055)\end{array}$ & $\begin{array}{c}-0.0254^{* * *} \\
(0.0077)\end{array}$ & $\begin{array}{c}-0.0259^{* * *} \\
(0.0078)\end{array}$ & $\begin{array}{c}-0.0258^{* * *} * \\
(0.0077)\end{array}$ \\
\hline$q_{t-2}$ & & & $\begin{array}{c}-0.0412^{* *} \\
(0.0183)\end{array}$ & $\begin{array}{l}-0.0295 \\
(0.0252)\end{array}$ & $\begin{array}{c}-0.0982^{* * *} \\
(0.0193)\end{array}$ & $\begin{array}{c}-0.112^{* * *} * \\
(0.0284)\end{array}$ \\
\hline$q_{t-2}^{2}$ & & & & $\begin{array}{c}-0.0009 \\
(0.0034)\end{array}$ & $\begin{array}{c}0.0005 \\
(0.0036)\end{array}$ & $\begin{array}{c}0.0016 \\
(0.0043)\end{array}$ \\
\hline$q_{t-3}$ & & & & & $\begin{array}{c}0.0527 * * * \\
(0.0129)\end{array}$ & $\begin{array}{c}0.0712^{* * *} \\
(0.0119)\end{array}$ \\
\hline$q_{t-3}^{2}$ & & & & & & $\begin{array}{l}-0.00158 \\
(0.00135)\end{array}$ \\
\hline Constant & $\begin{array}{c}0.369^{* * *} \\
(0.0400)\end{array}$ & $\begin{array}{c}0.204^{* * *} \\
(0.0147)\end{array}$ & $\begin{array}{c}0.200^{* * *} \\
(0.0149)\end{array}$ & $\begin{array}{c}0.198^{* * *} \\
(0.0117)\end{array}$ & $\begin{array}{c}0.199^{* * *} \\
(0.0115)\end{array}$ & $\begin{array}{c}0.196^{* * *} \\
(0.0117)\end{array}$ \\
\hline Observations & 32,698 & 32,698 & 32,698 & 32,698 & 32,698 & 32,698 \\
\hline R-squared & 0.674 & 0.716 & 0.718 & 0.718 & 0.720 & 0.720 \\
\hline
\end{tabular}

Notes: Cluster-robust standard errors by firm are in parenthesis. ${ }^{* * *} \mathrm{p}<0.01,{ }^{* *} \mathrm{p}<0.05,{ }^{*} \mathrm{p}<0.1$. 
Table 4: Fixed-effects instrumental variables.

\begin{tabular}{|c|c|c|c|c|c|c|}
\hline Second stage & FEIV1 & FEIV2 & FEIV3 & FEIV4 & FEIV5 & FEIV6 \\
\hline$q$ & $\begin{array}{c}0.0420^{* * *} \\
(0.0027)\end{array}$ & $\begin{array}{c}0.0490^{* * *} \\
(0.0024)\end{array}$ & $\begin{array}{c}0.0506^{* * *} \\
(0.0026)\end{array}$ & $\begin{array}{c}0.0506^{* * *} \\
(0.0026)\end{array}$ & $\begin{array}{c}0.0496^{* * *} \\
(0.0026)\end{array}$ & $\begin{array}{c}0.0495^{* * *} \\
(0.0026)\end{array}$ \\
\hline$C F$ & $\begin{array}{c}0.038^{* * *} \\
(0.0012)\end{array}$ & $\begin{array}{c}0.039^{* * *} \\
(0.0012)\end{array}$ & $\begin{array}{c}0.039^{* * *} \\
(0.0012)\end{array}$ & $\begin{array}{c}0.039^{* * *} \\
(0.0012)\end{array}$ & $\begin{array}{c}0.039^{* * *} \\
(0.0012)\end{array}$ & $\begin{array}{c}0.0394^{* * *} * \\
(0.0012)\end{array}$ \\
\hline Constant & $\begin{array}{c}0.154^{* * *} \\
(0.0027)\end{array}$ & $\begin{array}{c}0.147^{* * *} \\
(0.0026)\end{array}$ & $\begin{array}{c}0.146^{* * *} \\
(0.0026)\end{array}$ & $\begin{array}{c}0.146^{* * *} \\
(0.0026)\end{array}$ & $\begin{array}{c}0.147^{* * *} \\
(0.0027)\end{array}$ & $\begin{array}{c}0.147^{* * *} \\
(0.0027)\end{array}$ \\
\hline Observations & 32,698 & 32,698 & 32,698 & 32,698 & 32,698 & 32,698 \\
\hline R-squared & 0.005 & 0.067 & 0.068 & 0.068 & 0.068 & 0.068 \\
\hline First stage & FEIV1 & FEIV2 & FEIV3 & FEIV4 & FEIV5 & FEIV6 \\
\hline$C F$ & $\begin{array}{c}-0.162^{* * *} \\
(0.0022)\end{array}$ & $\begin{array}{c}-0.167^{* * *} \\
(0.0021)\end{array}$ & $\begin{array}{c}-0.168^{* * * *} \\
(0.0021)\end{array}$ & $\begin{array}{c}-0.168^{* * * *} \\
(0.0022)\end{array}$ & $\begin{array}{c}-0.168^{* * *} \\
(0.0021)\end{array}$ & $\begin{array}{c}-0.168^{* * * *} \\
(0.0021)\end{array}$ \\
\hline$q_{t-1}$ & $\begin{array}{c}0.511^{* * *} \\
(0.0026)\end{array}$ & $\begin{array}{c}0.674^{* * *} \\
(0.045)\end{array}$ & $\begin{array}{c}0.712^{* * *} \\
(0.006)\end{array}$ & $\begin{array}{c}0.719 * * * \\
(0.0068)\end{array}$ & $\begin{array}{c}0.728^{* * *} \\
(0.0068)\end{array}$ & $\begin{array}{c}0.728^{* * *} \\
(0.0068)\end{array}$ \\
\hline$q_{t-1}^{2}$ & & $\begin{array}{c}-0.016^{* * *} \\
(0.0004)\end{array}$ & $\begin{array}{c}-0.017^{* * *} \\
(0.0004)\end{array}$ & $\begin{array}{c}-0.0179^{* * *} \\
(0.0004)\end{array}$ & $\begin{array}{c}-0.0183^{* * *} \\
(0.0004)\end{array}$ & $\begin{array}{c}-0.0183^{* *} \\
(0.0004)\end{array}$ \\
\hline$q_{t-2}$ & & & $\begin{array}{c}-0.032^{* * *} \\
(0.0034)\end{array}$ & $\begin{array}{c}-0.0426^{* * *} \\
(0.0058)\end{array}$ & $\begin{array}{c}-0.0982^{* * *} \\
(0.0070)\end{array}$ & $\begin{array}{c}-0.100^{* * *} \\
(0.0076)\end{array}$ \\
\hline$q_{t-2}^{2}$ & & & $(0.0004)$ & $\begin{array}{c}0.0008 \\
(0.0043)\end{array}$ & $\begin{array}{c}0.0021 \\
(0.0004)\end{array}$ & $\begin{array}{c}0.0022 \\
(0.0046)\end{array}$ \\
\hline$q_{t-3}$ & & & & & $\begin{array}{c}0.0452^{* * *} \\
(0.0032)\end{array}$ & $\begin{array}{c}0.0481^{* * *} \\
(0.0055)\end{array}$ \\
\hline$q_{t-3}^{2}$ & & & & & & $\begin{array}{l}-0.0002 \\
(0.0004)\end{array}$ \\
\hline Constant & $\begin{array}{c}0.354^{* * *} \\
(0.003)\end{array}$ & $\begin{array}{c}0.196^{* * *} \\
(0.0041)\end{array}$ & $\begin{array}{c}0.352^{* * *} \\
(0.0042)\end{array}$ & $\begin{array}{c}0.352^{* * *} \\
(0.0044)\end{array}$ & $\begin{array}{c}0.353^{* * *} \\
(0.0044)\end{array}$ & $\begin{array}{c}0.353^{* * *} * \\
(0.0046)\end{array}$ \\
\hline Observations & 32,698 & 32,698 & 32,698 & 32,698 & 32,698 & 32,698 \\
\hline R-squared & 0.577 & 0.604 & 0.605 & 0.605 & 0.720 & 0.720 \\
\hline
\end{tabular}

Notes: Cluster-robust standard errors by firm are in parenthesis. ${ }^{* * *} \mathrm{p}<0.01,{ }^{* *} \mathrm{p}<0.05,{ }^{*} \mathrm{p}<0.1$.

Table 5: Arellano and Bond (1991) tests for autocorrelation in the residuals.

\begin{tabular}{ccccccccc}
\hline AR & z & p-value & z & p-value & z & p-value & z & p-value \\
\hline & OLS & & FE & & IV6 & & FEIV6 & \\
\hline 1 & 73.14 & 0.000 & 47.66 & 0.000 & 18.78 & 0.000 & 18.82 & 0.000 \\
2 & 43.23 & 0.000 & 11.80 & 0.000 & 12.71 & 0.000 & 7.61 & 0.000 \\
3 & 30.74 & 0.000 & -0.30 & 0.764 & 10.61 & 0.000 & -1.12 & 0.265 \\
\hline
\end{tabular}

Notes: Arellano and Bond (1991) tests for autocorrelation in equation $y_{i t}=\alpha+\beta q_{i t}+\gamma C F_{i t}+\varepsilon_{i t}$. 
Table 6: S-estimator.

\begin{tabular}{|c|c|c|c|c|c|c|}
\hline & S1 & $\mathrm{S} 2$ & S3 & $\mathrm{S} 4$ & S5 & S6 \\
\hline$q$ & $\begin{array}{c}0.1519^{* * *} \\
(0.042)\end{array}$ & $\begin{array}{c}0.1748^{* * *} \\
(0.031)\end{array}$ & $\begin{array}{c}0.1751^{* * *} \\
(0.031)\end{array}$ & $\begin{array}{c}0.1760^{* * *} \\
(0.030)\end{array}$ & $\begin{array}{c}0.1762^{* * *} \\
(0.030)\end{array}$ & $\begin{array}{c}0.1764^{* * *} \\
(0.030)\end{array}$ \\
\hline$C F$ & $\begin{array}{c}0.0555^{* * * *} \\
(0.001)\end{array}$ & $\begin{array}{c}0.0554^{* * *} \\
(0.001)\end{array}$ & $\begin{array}{c}0.0554^{* * *} \\
(0.001)\end{array}$ & $\begin{array}{c}0.0554^{* * * *} \\
(0.001)\end{array}$ & $\begin{array}{c}0.0554^{* * *} \\
(0.001)\end{array}$ & $\begin{array}{c}0.0554^{* * *} \\
(0.001)\end{array}$ \\
\hline Const. & $\begin{array}{c}0.0466^{* * *} \\
(0.040)\end{array}$ & $\begin{array}{c}0.0250^{* * *} \\
(0.030)\end{array}$ & $\begin{array}{c}0.0248^{* * *} \\
(0.029)\end{array}$ & $\begin{array}{c}0.0239^{* * *} \\
(0.029)\end{array}$ & $\begin{array}{c}0.0238^{* * *} \\
(0.029)\end{array}$ & $\begin{array}{c}0.0235^{* * *} \\
(0.028)\end{array}$ \\
\hline$q_{t-1}$ & $\begin{array}{c}-0.0950^{* *} \\
(0.034)\end{array}$ & $\begin{array}{c}0.0020 \\
(0.021)\end{array}$ & $\begin{array}{c}0.0759 \\
(0.043)\end{array}$ & $\begin{array}{c}-0.0303 \\
(0.054)\end{array}$ & $\begin{array}{c}-0.0390 \\
(0.054)\end{array}$ & $\begin{array}{l}-0.0488 \\
(0.057)\end{array}$ \\
\hline$q_{t-1}^{2}$ & & $\begin{array}{c}-0.0349 * * * \\
(0.013)\end{array}$ & $\begin{array}{c}-0.0362^{* * *} \\
(0.012)\end{array}$ & $\begin{array}{c}-0.0288^{* * *} \\
(0.015)\end{array}$ & $\begin{array}{c}-0.0284^{* * *} \\
(0.015)\end{array}$ & $\begin{array}{c}-0.0278^{* *} \\
(0.015)\end{array}$ \\
\hline$q_{t-2}$ & & & $\begin{array}{c}-0.0682 \\
(0.055)\end{array}$ & $\begin{array}{c}0.0399 \\
(0.045)\end{array}$ & $\begin{array}{c}0.0883^{* * * *} \\
(0.049)\end{array}$ & $\begin{array}{c}0.0469 \\
(0.040)\end{array}$ \\
\hline$q_{t-2}^{2}$ & & & & $\begin{array}{c}-0.0088 \\
(0.008)\end{array}$ & $\begin{array}{c}-0.0099 \\
(0.008)\end{array}$ & $\begin{array}{c}-0.0067^{* * *} \\
(0.007)\end{array}$ \\
\hline$q_{t-3}$ & & & & & $\begin{array}{c}-0.0372^{* * *} \\
(0.014)\end{array}$ & $\begin{array}{c}0.0144 \\
(0.022)\end{array}$ \\
\hline$q_{t-3}^{2}$ & & & & & & $\begin{array}{c}-0.0044 \\
(0.003)\end{array}$ \\
\hline Observations & 32,698 & 32,698 & 32,698 & 32,698 & 32,698 & 32,698 \\
\hline
\end{tabular}

Notes: Standard errors in parentheses. ${ }^{* * *} \mathrm{p}<0.01,{ }^{* *} \mathrm{p}<0.05,{ }^{*} \mathrm{p}<0.1$. 
Table 7: S-estimator using demeaned variables.

\begin{tabular}{|c|c|c|c|c|c|c|}
\hline & SFE1 & SFE2 & SFE3 & SFE4 & SFE5 & SFE6 \\
\hline \multirow[t]{2}{*}{$q$} & $0.173^{* * *}$ & $0.184^{* * *}$ & $0.184^{* * *}$ & $0.185^{* * *}$ & $0.185^{* * *}$ & $0.186^{* * *}$ \\
\hline & $(0.041)$ & $(0.036)$ & $(0.036)$ & $(0.036)$ & $(0.036)$ & $(0.035)$ \\
\hline \multirow[t]{2}{*}{$C F$} & $0.0551^{* * *}$ & $0.0563^{* * *}$ & $0.0564^{* * *}$ & $0.0565 * * *$ & $0.0565^{* * *}$ & $0.0565 * * *$ \\
\hline & $(0.004)$ & $(0.004)$ & $(0.004)$ & $(0.004)$ & $(0.004)$ & $(0.004)$ \\
\hline \multirow[t]{2}{*}{ Constant } & 0.0115 & 0.0126 & 0.0126 & 0.0127 & 0.0128 & 0.0128 \\
\hline & $(0.004)$ & $(0.004)$ & $(0.004)$ & $(0.003)$ & $(0.003)$ & $(0.003)$ \\
\hline \multirow[t]{2}{*}{$q_{t-1}$} & $-0.0701 * * *$ & 0.0249 & $0.0623^{* * *}$ & 0.0225 & 0.0131 & 0.0118 \\
\hline & $(0.027)$ & $(0.026)$ & $(0.021)$ & $(0.025)$ & $(0.025)$ & $(0.025)$ \\
\hline \multirow{2}{*}{$q_{t-1}^{2}$} & & $-0.0221^{* * *}$ & $-0.0230^{* * *}$ & $-0.0193^{*}$ & $-0.0188^{*}$ & $-0.0185^{*}$ \\
\hline & & $(0.012)$ & $(0.011)$ & $(0.012)$ & $(0.011)$ & $(0.011)$ \\
\hline \multirow[t]{2}{*}{$q_{t-2}$} & & & -0.0384 & 0.0164 & $0.0465^{* * *}$ & $0.0320 * * *$ \\
\hline & & & $(0.024)$ & $(0.014)$ & $(0.018)$ & $(0.018)$ \\
\hline \multirow[t]{2}{*}{$q_{t-2}^{2}$} & & & & $-0.0071^{* * *}$ & $-0.0080^{*}$ & -0.0065 \\
\hline & & & & $(0.005)$ & $(0.005)$ & $(0.005)$ \\
\hline \multirow[t]{2}{*}{$q_{t-3}$} & & & & & $-0.0238^{* * *}$ & $-0.0026^{* * *}$ \\
\hline & & & & & $(0.011)$ & $(0.012)$ \\
\hline \multirow[t]{2}{*}{$q_{t-3}^{2}$} & & & & & & -0.0028 \\
\hline & & & & & & $(0.002)$ \\
\hline Observations & 32,698 & 32,698 & 32,698 & 32,698 & 32,698 & 32,698 \\
\hline
\end{tabular}

Notes: Standard errors in parentheses. ${ }^{* * *} \mathrm{p}<0.01,{ }^{* *} \mathrm{p}<0.05,{ }^{*} \mathrm{p}<0.1$. All variables are previously demeaned with the within transformation. 
Table 8: Investment model for unconstrained firms characterized by high and low payout ratios.

\begin{tabular}{lcccccc}
\hline VARIABLES & OLS & FE & IV6 & FEIV6 & SE6 & SFE6 \\
\hline \multicolumn{7}{c}{ High payout ratios (unconstrained) } \\
\hline$q$ & $0.0291^{* * *}$ & $0.0330^{* * *}$ & $0.0233^{* * *}$ & $0.0230^{* * *}$ & $0.0333^{* * *}$ & $0.0244^{* * *}$ \\
& $(0.0048)$ & $(0.0053)$ & $(0.0055)$ & $(0.0050)$ & $(0.0049)$ & $(0.0050)$ \\
Constant & $0.0802^{* * *}$ & $0.0679^{* * *}$ & $0.0817^{* * *}$ & $0.0898^{* * *}$ & $0.0790^{* * *}$ & $0.0689^{* * *}$ \\
& $(0.0102)$ & $(0.0107)$ & $(0.0106)$ & $(0.0099)$ & $(0.0013)$ & $(0.0010)$ \\
& $0.135^{* * *}$ & $0.136^{* * *}$ & $0.140^{* * *}$ & $0.136^{* * *}$ & $0.131^{* * *}$ & $-0.008^{* * *}$ \\
& $(0.0044)$ & $(0.0058)$ & $(0.0049)$ & $(0.0041)$ & $(0.0042)$ & $(0.0007)$ \\
Observations & 11,643 & 11,643 & 11,643 & 11,643 & 11,643 & 11,643 \\
\hline$q$ & $0.1393^{* * *}$ & $0.1432^{* * *}$ & $0.1140^{* * *}$ & $0.1231^{* * *}$ & $0.2243^{* * *}$ & $0.2209^{* * *}$ \\
& $(0.0144)$ & $(0.0213)$ & $(0.0122)$ & $(0.0133)$ & $(0.0498)$ & $(0.0478)$ \\
CF & $0.0520^{* * *}$ & $0.0462^{* * *}$ & $0.0478^{* * *}$ & $0.0670^{* * *}$ & $0.0664^{* * *}$ & $0.0625^{* * *}$ \\
Constant & $(0.0100)$ & $(0.0079)$ & $(0.0118)$ & $(0.0199)$ & $(0.0083)$ & $(0.0090)$ \\
& $0.0625^{* * *}$ & $0.0602^{* * *}$ & $0.0850^{* * *}$ & $0.0721^{* * *}$ & $-0.0146^{* * *}$ & $-0.0028^{* * *}$ \\
& $(0.0115)$ & $(0.0195)$ & $(0.0101)$ & $(0.0093)$ & $(0.0450)$ & $(0.0040)$ \\
Observations & 9,383 & 9,383 & 9,383 & 9,383 & 9,383 & 9,383 \\
\hline
\end{tabular}

Notes: Cluster-robust standard errors by firm are in parenthesis. ${ }^{* * *} \mathrm{p}<0.01,{ }^{* *} \mathrm{p}<0.05,{ }^{*} \mathrm{p}<0.1$.

Table 9: Investment model for unconstrained firms characterized by large and small size.

\begin{tabular}{|c|c|c|c|c|c|c|}
\hline VARIABLES & OLS & $\mathrm{FE}$ & IV6 & FEIV6 & SE6 & SFE6 \\
\hline \multicolumn{7}{|c|}{ Large size (unconstrained) } \\
\hline$q$ & $\begin{array}{c}0.0425^{* * *} \\
(0.0061)\end{array}$ & $\begin{array}{c}0.0484^{* * *} \\
(0.0058)\end{array}$ & $\begin{array}{c}0.0406^{* * *} \\
(0.0067)\end{array}$ & $\begin{array}{c}0.0417^{* * *} \\
(0.0028)\end{array}$ & $\begin{array}{c}0.0350^{* * *} \\
(0.0055)\end{array}$ & $\begin{array}{c}0.0343 * * * \\
(0.0042)\end{array}$ \\
\hline$C F$ & $\begin{array}{c}0.0772^{* * *} \\
(0.0125)\end{array}$ & $\begin{array}{c}0.0571^{* * *} \\
(0.0119)\end{array}$ & $\begin{array}{c}0.0775^{* * *} \\
(0.0126)\end{array}$ & $\begin{array}{c}0.0574^{* * *} * \\
(0.0023)\end{array}$ & $\begin{array}{c}0.0784^{* * *} \\
(0.0009)\end{array}$ & $\begin{array}{c}0.0578^{* * *} * \\
(0.0002)\end{array}$ \\
\hline Constant & $\begin{array}{c}0.128^{* * *} \\
(0.0059)\end{array}$ & $\begin{array}{c}0.129^{* * *} \\
(0.0067)\end{array}$ & $\begin{array}{c}0.130 * * * \\
(0.0061)\end{array}$ & $\begin{array}{c}0.135^{* * *} \\
(0.0030)\end{array}$ & $\begin{array}{c}0.135^{* * *} \\
(0.0050)\end{array}$ & $\begin{array}{c}0.002^{* * *} \\
(0.0003)\end{array}$ \\
\hline Observations & 10,839 & 10,839 & 10,839 & 10,839 & 10,839 & 10,839 \\
\hline \multicolumn{7}{|c|}{ Small size (constrained) } \\
\hline$q$ & $\begin{array}{c}0.0707^{* * *} \\
(0.0102)\end{array}$ & $\begin{array}{c}0.0709^{* * *} \\
(0.0116)\end{array}$ & $\begin{array}{c}0.0450^{* * *} \\
(0.0081)\end{array}$ & $\begin{array}{c}0.0250^{* * *} \\
(0.0057)\end{array}$ & $\begin{array}{c}0.0513^{* * *} \\
(0.0103)\end{array}$ & $\begin{array}{c}0.0222^{* * *} \\
(0.0070)\end{array}$ \\
\hline$C F$ & $\begin{array}{c}0.119^{* * *} \\
(0.0110)\end{array}$ & $\begin{array}{c}0.142^{* * *} \\
(0.0146)\end{array}$ & $\begin{array}{c}0.127^{* * *} \\
(0.0116)\end{array}$ & $\begin{array}{c}0.154^{* * *} \\
(0.0153)\end{array}$ & $\begin{array}{c}0.1252^{* * *} \\
(0.0033)\end{array}$ & $\begin{array}{c}0.1539^{* * *} \\
(0.0018)\end{array}$ \\
\hline Constant & $\begin{array}{c}0.112^{* * *} \\
(0.0079)\end{array}$ & $\begin{array}{c}0.104^{* * *} \\
(0.0099)\end{array}$ & $\begin{array}{c}0.132^{* * *} \\
(0.0064)\end{array}$ & $\begin{array}{c}0.140^{* * *} \\
(0.0050)\end{array}$ & $\begin{array}{c}0.1273^{* * *} \\
(0.0079)\end{array}$ & $\begin{array}{c}-0.0048^{* * *} \\
(0.0007)\end{array}$ \\
\hline Observations & 9,805 & 9,805 & 9,805 & 9,805 & 9,805 & 9,805 \\
\hline
\end{tabular}

Notes: Cluster-robust standard errors by firm are in parenthesis. ${ }^{* * *} \mathrm{p}<0.01,{ }^{* *} \mathrm{p}<0.05,{ }^{*} \mathrm{p}<0.1$. 
Table 10: Investment model for unconstrained firms characterized by high and low dividend payments.

\begin{tabular}{|c|c|c|c|c|c|c|}
\hline VARIABLES & OLS & $\mathrm{FE}$ & IV6 & FEIV6 & SE6 & SFE6 \\
\hline \multicolumn{7}{|c|}{ High dividend payments (unconstrained) } \\
\hline$q$ & $\begin{array}{c}0.0333^{* * *} \\
(0.0047)\end{array}$ & $\begin{array}{c}0.0412^{* * *} \\
(0.0048)\end{array}$ & $\begin{array}{c}0.0251^{* * *} \\
(0.0051)\end{array}$ & $\begin{array}{c}0.0271^{* * *} \\
(0.0024)\end{array}$ & $\begin{array}{c}0.0369^{* * *} \\
(0.0040)\end{array}$ & $\begin{array}{c}0.0028 \\
(0.0041)\end{array}$ \\
\hline$C F$ & $\begin{array}{c}0.0918^{* * *} \\
(0.0100)\end{array}$ & $\begin{array}{c}0.0777^{* * *} \\
(0.0137)\end{array}$ & $\begin{array}{c}0.0946^{* * *} \\
(0.0102)\end{array}$ & $\begin{array}{c}0.0807^{* * *} \\
(0.0032)\end{array}$ & $\begin{array}{c}0.0905^{* * *} \\
(0.0013)\end{array}$ & $\begin{array}{c}0.0807^{* * *} \\
(0.0008)\end{array}$ \\
\hline Constant & $\begin{array}{c}0.132^{* * *} \\
(0.0050)\end{array}$ & $\begin{array}{c}0.130^{* * *} \\
(0.0068)\end{array}$ & $\begin{array}{c}0.140^{* * *} \\
(0.0053)\end{array}$ & $\begin{array}{c}0.143^{* * *} \\
(0.0028)\end{array}$ & $\begin{array}{c}0.1290^{* * *} \\
(0.0036)\end{array}$ & $\begin{array}{c}0.0004 \\
(0.0005)\end{array}$ \\
\hline Observations & 11,292 & 11,292 & 11,292 & 11,292 & 11,292 & 11,292 \\
\hline \multicolumn{7}{|c|}{ Low dividend payments (constrained) } \\
\hline$q$ & $\begin{array}{c}0.1362^{* * *} \\
(0.0136)\end{array}$ & $\begin{array}{c}0.1590^{* * *} \\
(0.0180)\end{array}$ & $\begin{array}{c}0.1011^{* * *} \\
(0.0127)\end{array}$ & $\begin{array}{c}0.1160^{* * *} \\
(0.0124)\end{array}$ & $\begin{array}{c}0.2179^{* * *} \\
(0.0251)\end{array}$ & $\begin{array}{c}0.2007^{* * *} \\
(0.0159)\end{array}$ \\
\hline$C F$ & $\begin{array}{c}0.0504^{* * *} \\
(0.0080)\end{array}$ & $\begin{array}{c}0.0464^{* * *} \\
(0.0055)\end{array}$ & $\begin{array}{c}0.0457^{* * *} \\
(0.0109)\end{array}$ & $\begin{array}{c}0.0384^{* * * *} \\
(0.0028)\end{array}$ & $\begin{array}{c}0.0614^{* * *} \\
(0.0033)\end{array}$ & $\begin{array}{c}0.0549 * * * \\
(0.0027)\end{array}$ \\
\hline Constant & $\begin{array}{c}0.0761^{* * *} * \\
(0.0105)\end{array}$ & $\begin{array}{c}0.0571^{* * * *} \\
(0.0167)\end{array}$ & $\begin{array}{c}0.108^{* * *} \\
(0.0106)\end{array}$ & $\begin{array}{c}0.0968^{* * *} \\
(0.0114)\end{array}$ & $\begin{array}{c}0.0023^{* * *} \\
(0.0226)\end{array}$ & $\begin{array}{c}-0.0035^{* * * *} \\
(0.0010)\end{array}$ \\
\hline Observations & 9,597 & 9,597 & 9,597 & 9,597 & 9,597 & 9,597 \\
\hline
\end{tabular}

Notes: Cluster-robust standard errors by firm are in parenthesis. ${ }^{* * *} \mathrm{p}<0.01,{ }^{* *} \mathrm{p}<0.05,{ }^{*} \mathrm{p}<0.1$.

Table 11: Investment model for unconstrained and constrained firms characterized by the Hadlock-Pierce index.

\begin{tabular}{|c|c|c|c|c|c|c|}
\hline VARIABLES & OLS & $\mathrm{FE}$ & IV6 & FEIV6 & SE6 & SFE6 \\
\hline \multicolumn{7}{|c|}{ Low HP index (unconstrained) } \\
\hline$q$ & $0.0522^{* * *}$ & $0.0608^{* * *}$ & $0.0433^{* * *}$ & $0.0460^{* * *}$ & $0.0450^{* * *}$ & $0.0398^{* * *}$ \\
\hline$C F$ & $\begin{array}{c}(0.0071) \\
0.076^{* * *}\end{array}$ & $\begin{array}{c}(0.0074) \\
0.057^{* * *}\end{array}$ & $\begin{array}{c}(0.0068) \\
0.078^{* * *}\end{array}$ & $\begin{array}{c}(0.0035) \\
0.058^{* * *}\end{array}$ & $\begin{array}{c}(0.0070) \\
0.077^{* * *}\end{array}$ & $\begin{array}{c}(0.0047) \\
0.065^{* * *}\end{array}$ \\
\hline & $(0.0102)$ & $(0.0114)$ & $(0.0107)$ & $(0.0030)$ & $(0.0012)$ & $(0.0004)$ \\
\hline Constant & $\begin{array}{c}-0.123^{* * *} \\
(0.0069)\end{array}$ & $\begin{array}{c}0.131^{* * *} \\
(0.0082)\end{array}$ & $\begin{array}{c}0.132^{* * *} \\
(0.0062)\end{array}$ & $\begin{array}{c}0.136^{* * *} \\
(0.0037)\end{array}$ & $\begin{array}{c}0.129^{* * *} \\
(0.0065)\end{array}$ & $\begin{array}{c}-0.0013^{* * *} \\
(0.0005)\end{array}$ \\
\hline Observations & 11,012 & 11,012 & 11,012 & 11,012 & 11,012 & 11,012 \\
\hline \multicolumn{7}{|c|}{ High HP index (constrained) } \\
\hline$q$ & $\begin{array}{c}0.0575^{* * *} \\
(0.0098)\end{array}$ & $\begin{array}{c}0.0624^{* * * *} \\
(0.0096)\end{array}$ & $\begin{array}{c}0.0353^{* * *} \\
(0.0085)\end{array}$ & $\begin{array}{c}0.0127^{* * *} \\
(0.0085)\end{array}$ & $\begin{array}{c}0.0398^{* * *} \\
(0.0113)\end{array}$ & $\begin{array}{c}0.0336^{* * *} \\
(0.0127)\end{array}$ \\
\hline$C F$ & $\begin{array}{c}0.132^{* * *} \\
(0.110)\end{array}$ & $\begin{array}{c}0.142^{* * *} * \\
(0.0131)\end{array}$ & $\begin{array}{c}0.136^{* * *} \\
(0.0114)\end{array}$ & $\begin{array}{c}0.1523^{* * *} \\
(0.0061)\end{array}$ & $\begin{array}{c}0.1357^{* * *} \\
(0.0023)\end{array}$ & $\begin{array}{c}0.1324^{* * *} \\
(0.0015)\end{array}$ \\
\hline Constant & $\begin{array}{c}0.110^{* * *} \\
(0.0078)\end{array}$ & $\begin{array}{c}0.102^{\text {**** }} \\
(0.0081)\end{array}$ & $\begin{array}{c}0.123^{* * *} \\
(0.0068)\end{array}$ & $\begin{array}{c}0.141^{* * *} \\
(0.0069)\end{array}$ & $\begin{array}{c}0.123^{* * *} \\
(0.0087)\end{array}$ & $\begin{array}{c}-0.0039^{* * *} \\
(0.0009)\end{array}$ \\
\hline Observations & 8,435 & 8,435 & 8,435 & 8,435 & 8,435 & 8,435 \\
\hline
\end{tabular}

Notes: Cluster-robust standard errors by firm are in parenthesis. ${ }^{* * *} \mathrm{p}<0.01,{ }^{* *} \mathrm{p}<0.05,{ }^{*} \mathrm{p}<0.1$. 
Table 12: Arellano and Bond (1991) tests for autocorrelation in the residuals.

\begin{tabular}{|c|c|c|c|c|c|c|c|c|}
\hline $\mathrm{AR}$ & $\mathrm{z}$ & $\mathrm{p}$-value & $\mathrm{z}$ & $\mathrm{p}$-value & $\mathrm{Z}$ & $\mathrm{p}$-value & $\mathrm{z}$ & $\mathrm{p}$-value \\
\hline \multicolumn{9}{|c|}{ High payout } \\
\hline & OLS & & $\mathrm{FE}$ & & IV & & FEIV & \\
\hline 1 & 37.56 & 0.000 & 26.33 & 0.000 & 14.52 & 0.000 & 13.98 & 0.000 \\
\hline 2 & 21.27 & 0.000 & 8.25 & 0.000 & 10.32 & 0.000 & 5.46 & 0.000 \\
\hline 3 & 13.69 & 0.000 & 2.57 & 0.764 & 7.93 & 0.000 & 2.13 & 0.000 \\
\hline \multicolumn{9}{|c|}{ Low payout } \\
\hline & OLS & & $\mathrm{FE}$ & & IV & & FEIV & \\
\hline 1 & 35.26 & 0.000 & 22.13 & 0.000 & 9.35 & 0.000 & 12.74 & 0.000 \\
\hline 2 & 19.34 & 0.000 & 4.51 & 0.000 & 5.40 & 0.000 & 3.62 & 0.000 \\
\hline 3 & 15.43 & 0.000 & -0.15 & 0.882 & 4.56 & 0.000 & -0.41 & 0.685 \\
\hline \multicolumn{9}{|c|}{ Large size } \\
\hline & OLS & & $\mathrm{FE}$ & & IV & & FEIV & \\
\hline 1 & 61.06 & 0.000 & 45.62 & 0.000 & 13.19 & 0.000 & 12.48 & 0.000 \\
\hline 2 & 40.14 & 0.000 & 15.94 & 0.000 & 11.48 & 0.000 & 8.00 & 0.000 \\
\hline 3 & 30.90 & 0.000 & 4.44 & 0.000 & 9.74 & 0.000 & 2.56 & 0.010 \\
\hline \multicolumn{9}{|c|}{ Small size } \\
\hline & OLS & & $\mathrm{FE}$ & & IV & & FEIV & \\
\hline 1 & 34.63 & 0.000 & 21.43 & 0.000 & 11.30 & 0.000 & 10.89 & 0.000 \\
\hline 2 & 17.88 & 0.000 & 3.69 & 0.000 & 7.73 & 0.000 & 2.68 & 0.007 \\
\hline 3 & 11.95 & 0.000 & -1.75 & 0.081 & 5.92 & 0.000 & -1.78 & 0.076 \\
\hline \multicolumn{9}{|c|}{ High dividends } \\
\hline & OLS & & $\mathrm{FE}$ & & IV & & FEIV & \\
\hline 1 & 58.61 & 0.000 & 45.32 & 0.000 & 13.13 & 0.000 & 13.41 & 0.000 \\
\hline 2 & 36.93 & 0.000 & 16.86 & 0.000 & 10.73 & 0.000 & 8.64 & 0.000 \\
\hline 3 & 27.14 & 0.000 & 5.79 & 0.000 & 8.81 & 0.000 & 3.51 & 0.000 \\
\hline \multicolumn{9}{|c|}{ Low dividends } \\
\hline & OLS & & $\mathrm{FE}$ & & IV & & FEIV & \\
\hline 1 & 33.60 & 0.000 & 17.44 & 0.000 & 10.97 & 0.000 & 10.19 & 0.000 \\
\hline 2 & 20.04 & 0.000 & 2.34 & 0.019 & 6.46 & 0.000 & 1.50 & 0.133 \\
\hline 3 & 15.00 & 0.000 & -0.92 & 0.360 & 5.66 & 0.000 & -1.25 & 0.211 \\
\hline \multicolumn{9}{|c|}{ High HP index } \\
\hline & OLS & & $\mathrm{FE}$ & & IV & & FEIV & \\
\hline 1 & 25.31 & 0.000 & 16.10 & 0.000 & 12.91 & 0.000 & 7.93 & 0.000 \\
\hline 2 & 10.58 & 0.000 & 0.69 & 0.492 & 7.62 & 0.000 & 0.38 & 0.707 \\
\hline 3 & 5.39 & 0.000 & -2.92 & 0.003 & 4.68 & 0.000 & -2.10 & 0.000 \\
\hline \multicolumn{9}{|c|}{ Low HP index } \\
\hline & OLS & & $\mathrm{FE}$ & & IV & & FEIV & \\
\hline 1 & 46.87 & 0.000 & 30.72 & 0.000 & 12.19 & 0.000 & 5.96 & 0.000 \\
\hline 2 & 31.63 & 0.000 & 14.07 & 0.000 & 11.27 & 0.000 & 8.70 & 0.000 \\
\hline 3 & 25.73 & 0.000 & 6.89 & 0.000 & 9.56 & 0.000 & 4.83 & 0.000 \\
\hline
\end{tabular}

Notes: Arellano and Bond (1991) tests for autocorrelation for subsamples classified according to different criteria. 
Table 13: Investment model for low-payout firms before and after 1989.

\begin{tabular}{|c|c|c|c|c|c|c|}
\hline VARIABLES & OLS & $\mathrm{FE}$ & IV6 & FEIV6 & SE6 & SFE6 \\
\hline \multicolumn{7}{|c|}{ Before 1989} \\
\hline \multirow[t]{2}{*}{$q$} & $0.1075^{* * *}$ & $0.1000^{* * *}$ & $0.0710^{* * *}$ & $0.0427^{* * *}$ & $0.0852^{* * *}$ & $0.2184^{* * *}$ \\
\hline & $(0.0226)$ & $(0.0245)$ & $(0.0204)$ & $(0.0128)$ & $(0.0261)$ & $(0.0186)$ \\
\hline \multirow[t]{2}{*}{$C F$} & $0.184^{* * *}$ & $0.131^{* * *}$ & $0.193^{* * *}$ & $0.131^{* * *}$ & $0.190 * * *$ & $0.0588 * * *$ \\
\hline & $(0.0512)$ & $(0.0494)$ & $(0.0565)$ & $(0.0093)$ & $(0.0059)$ & $(0.0037)$ \\
\hline \multirow[t]{2}{*}{ Constant } & $0.078^{* * *}$ & $0.097^{* * *}$ & $0.110^{* * *}$ & $0.151^{* * *}$ & $0.098^{* * *}$ & $-0.0151^{* * *}$ \\
\hline & $(0.0173)$ & $(0.0228)$ & $(0.0152)$ & $(0.0123)$ & $(0.0230)$ & $(0.0015)$ \\
\hline \multirow[t]{2}{*}{ Observations } & 3,616 & 3,616 & 3,616 & 3,616 & 3,616 & 3,616 \\
\hline & & & After 1989 & & & \\
\hline \multirow[t]{2}{*}{$q$} & $0.132^{* * *}$ & $0.1615^{* * *}$ & $0.0938^{* * *}$ & $0.0970 * * *$ & $0.2323^{* * *}$ & $0.2184^{* * *}$ \\
\hline & $(0.0169)$ & $(0.0396)$ & $(0.0113)$ & $(0.0185)$ & $(0.0128)$ & $(0.0186)$ \\
\hline \multirow[t]{2}{*}{$C F$} & $0.044^{* * *}$ & $0.037^{* * *}$ & $0.127^{* * *}$ & $0.0341^{* * *}$ & $0.0633^{* * *}$ & $0.059 * * *$ \\
\hline & $(0.0071)$ & $(0.0088)$ & $(0.0116)$ & $(0.0043)$ & $(0.0024)$ & $(0.0037)$ \\
\hline \multirow[t]{2}{*}{ Constant } & $0.058^{* * *}$ & $0.092^{* * *}$ & $0.132^{* * *}$ & $0.090^{* * *}$ & $-0.0278^{* * *}$ & $-0.0150^{* * *}$ \\
\hline & $(0.0131)$ & $(0.0095)$ & $(0.0064)$ & $(0.0162)$ & $(0.0111)$ & $(0.0015)$ \\
\hline Observations & 5,767 & 5,767 & 5,767 & 5,767 & 5,767 & 5,767 \\
\hline
\end{tabular}

Notes: Cluster-robust standard errors by firm are in parenthesis. ${ }^{* * *} \mathrm{p}<0.01,{ }^{* *} \mathrm{p}<0.05,{ }^{*} \mathrm{p}<0.1$.

Table 14: Investment model for small firms before and after 1989.

\begin{tabular}{|c|c|c|c|c|c|c|}
\hline VARIABLES & OLS & $\mathrm{FE}$ & IV6 & FEIV6 & SE6 & SFE6 \\
\hline \multicolumn{7}{|c|}{ Before 1989} \\
\hline \multirow[t]{2}{*}{$q$} & $0.0428^{* * *}$ & $0.0309^{* * *}$ & $0.0174^{* * *}$ & $-0.0002^{* * *}$ & $0.0385^{* * *}$ & $0.0145^{* * *}$ \\
\hline & $(0.0107)$ & $(0.0099)$ & $(0.0073)$ & $(0.0075)$ & $(0.0115)$ & $(0.0069)$ \\
\hline \multirow[t]{2}{*}{$C F$} & $0.220^{* * *}$ & $0.303^{* * *}$ & $0.242^{* * *}$ & $0.324^{* * *}$ & $0.224^{* * *}$ & $0.292^{* * *}$ \\
\hline & $(0.0181)$ & $(0.0200)$ & $(0.0186)$ & $(0.0137)$ & $(0.0098)$ & $(0.0047)$ \\
\hline \multirow[t]{2}{*}{ Constant } & $0.115^{* * *}$ & $0.097^{* * *}$ & $0.132^{* * *}$ & $0.120^{* * *}$ & $0.118^{* * *}$ & $0.007^{* * *}$ \\
\hline & $(0.0092)$ & $(0.0100)$ & $(0.0071)$ & $(0.0073)$ & $(0.0076)$ & $(0.0007)$ \\
\hline Observations & 4,140 & 4,140 & 4,140 & 4,140 & 4,140 & 4,140 \\
\hline \multicolumn{7}{|c|}{ After 1989} \\
\hline \multirow[t]{2}{*}{$q$} & $0.0901^{* * *}$ & $0.1268^{* * *}$ & $0.0522^{* * *}$ & $0.0384^{* * *}$ & $0.0837^{* * *}$ & 0.0088 \\
\hline & $(0.0127)$ & $(0.0160)$ & $(0.0146)$ & $(0.0174)$ & $(0.0187)$ & $(0.0214)$ \\
\hline \multirow[t]{2}{*}{$C F$} & $0.097^{* * *}$ & $0.105^{* * *}$ & $0.104^{* * *}$ & $0.117^{* * *}$ & $0.098^{* * *}$ & $0.1104^{* * *}$ \\
\hline & $(0.0108)$ & $(0.0133)$ & $(0.0117)$ & $(0.0057)$ & $(0.0036)$ & $(0.0034)$ \\
\hline \multirow[t]{2}{*}{ Constant } & $0.096^{* * *}$ & $0.063^{* * *}$ & $0.124^{* * *}$ & $0.131^{* * *}$ & $0.1006^{* * *}$ & $-0.0091^{* * *}$ \\
\hline & $(0.0096)$ & $(0.0126)$ & $(0.0107)$ & $(0.0135)$ & $(0.0139)$ & $(0.0021)$ \\
\hline Observations & 5,665 & 5,665 & 5,665 & 5,665 & 5,665 & 5,665 \\
\hline
\end{tabular}

Notes: Cluster-robust standard errors by firm are in parenthesis. ${ }^{* * *} \mathrm{p}<0.01,{ }^{* *} \mathrm{p}<0.05,{ }^{*} \mathrm{p}<0.1$. 
Figure 1: Lag of Tobin's q as a function of OLS residuals and Tobin's $q$
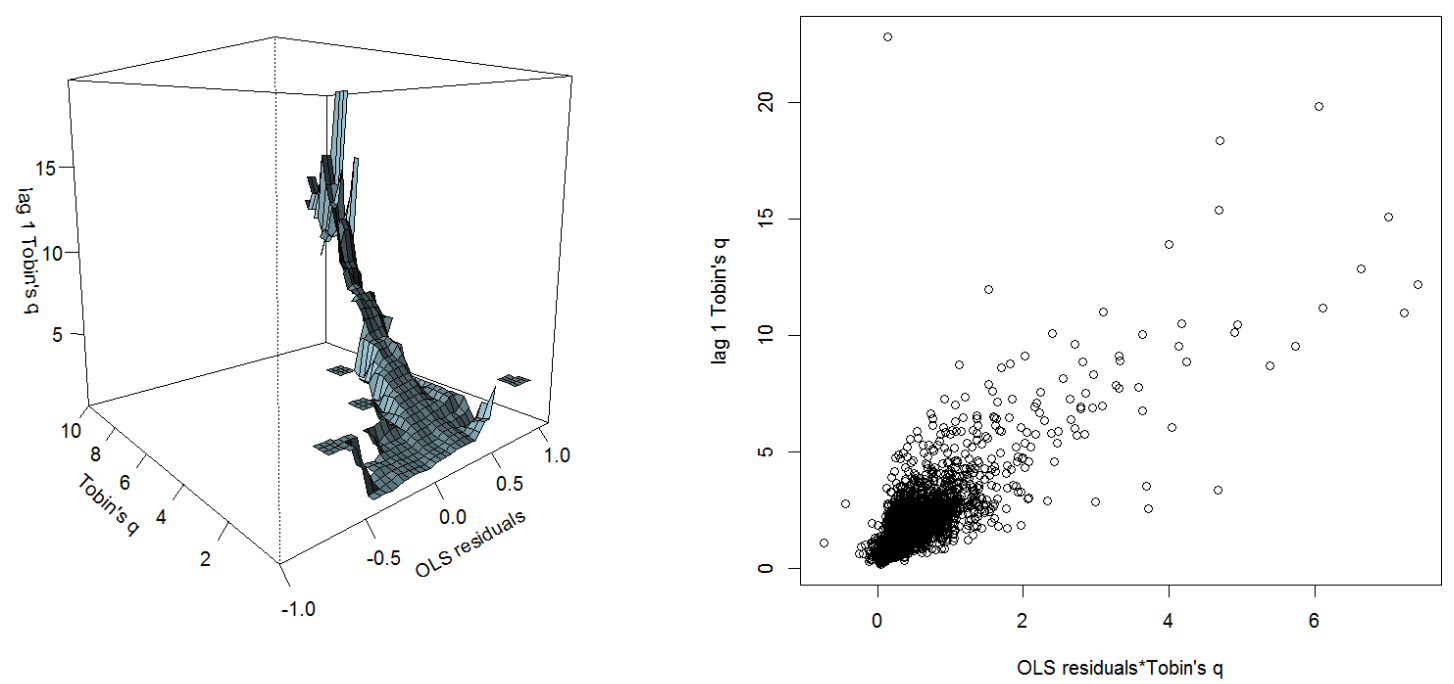

Notes: Left panel: Consider $\mathcal{G}_{q}$ and $\mathcal{G}_{\varepsilon}$, grids of size 50 of spaced points on the range of $q_{t}$ and the OLS residuals $\widehat{\varepsilon}_{t}$. Then on the plane given by $\mathcal{G}_{q} \times \mathcal{G}_{\varepsilon}$ with element $\left(g_{q}(h), g_{\varepsilon}(j)\right), h, j=$ $1,2, \ldots, 50$, we compute the average $q_{t-1}$ of all observations with $g_{q}(h-2) \leq q_{t-1}<g_{q}(h+2)$ and $g_{\varepsilon}(j) \leq q_{t-1} \widehat{\varepsilon}<g_{\varepsilon}(j)$. Empty areas correspond to $(\widehat{\varepsilon}, q)$ cells with no observations. Right panel: Horizontal axis: $q_{t}$ multiplied by the OLS residuals $\widehat{\varepsilon}_{t}$. Vertical axis: $q_{t-1}$. 